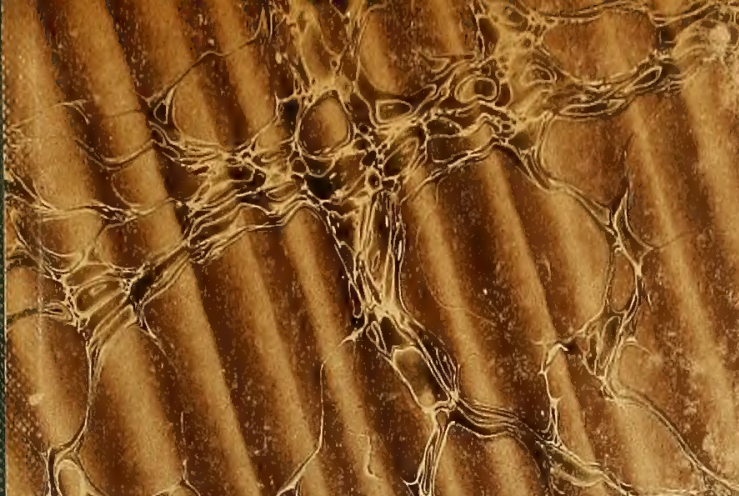

\title{
H. W.
}

Af

\section{SYST. SILURIEN DE LAMÉRIOUE SEPTENTR.}

ras

in.

$\frac{\overline{\text { ATLAS }}}{1843 .}, 19 \mathrm{~s}$

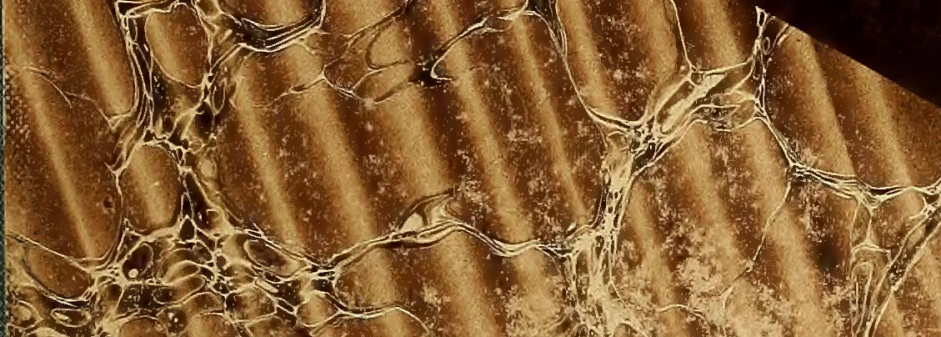

S.

S. (1) in 10 - 10 


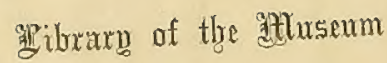

OF

COMPARATIVE ZOÖLOGY,

AT IARVARD COLLGE, CAIBRIDGE, JIASS.

Jouroed by pribate subscription, in 1861.

DR. L. DE KONINCK'S LIBRARY.

No. 1812 




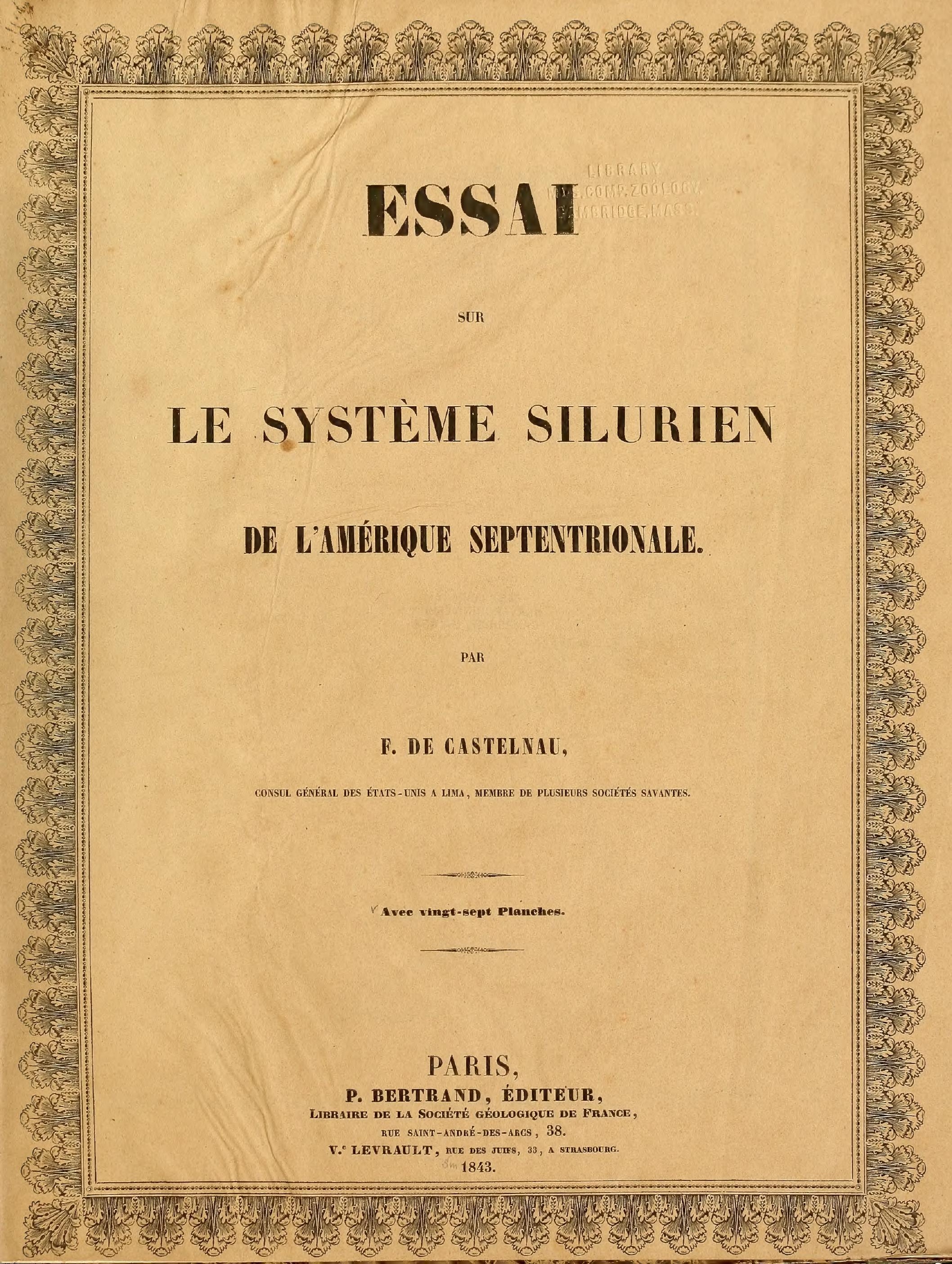


रुकासी हो

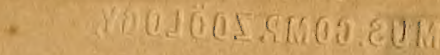

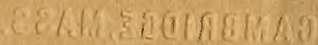

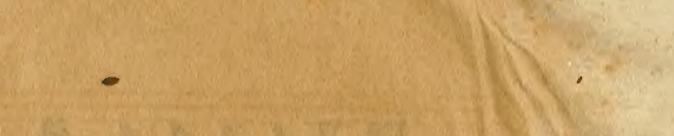

16.

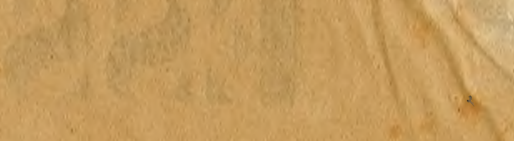

MCZ LIBRARY

HARVARD UNIVERSITY

CAMBRIDGE. MA USA

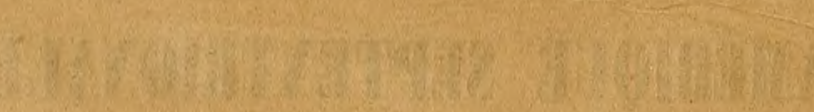
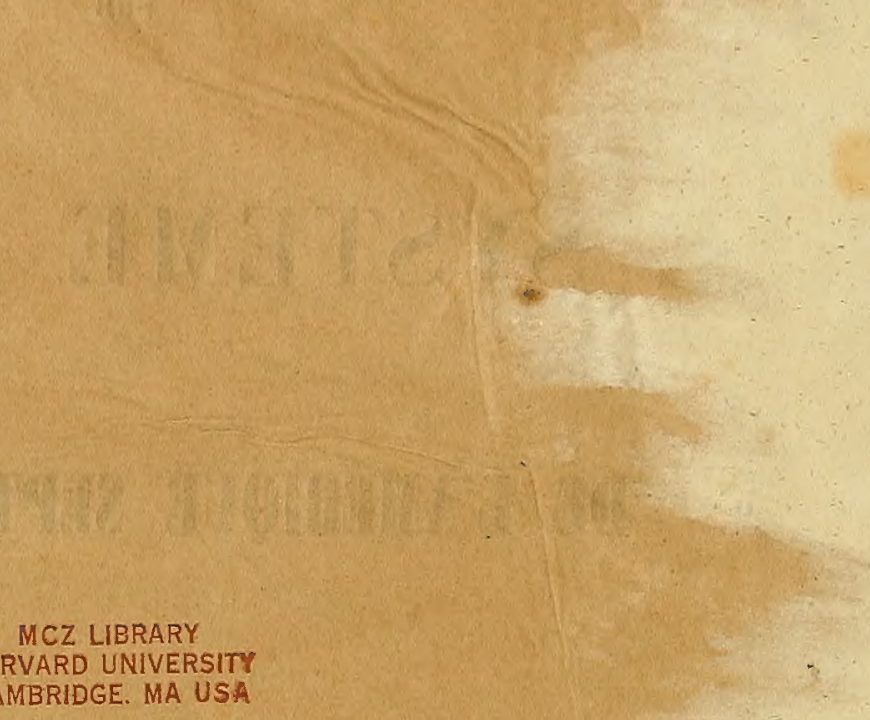


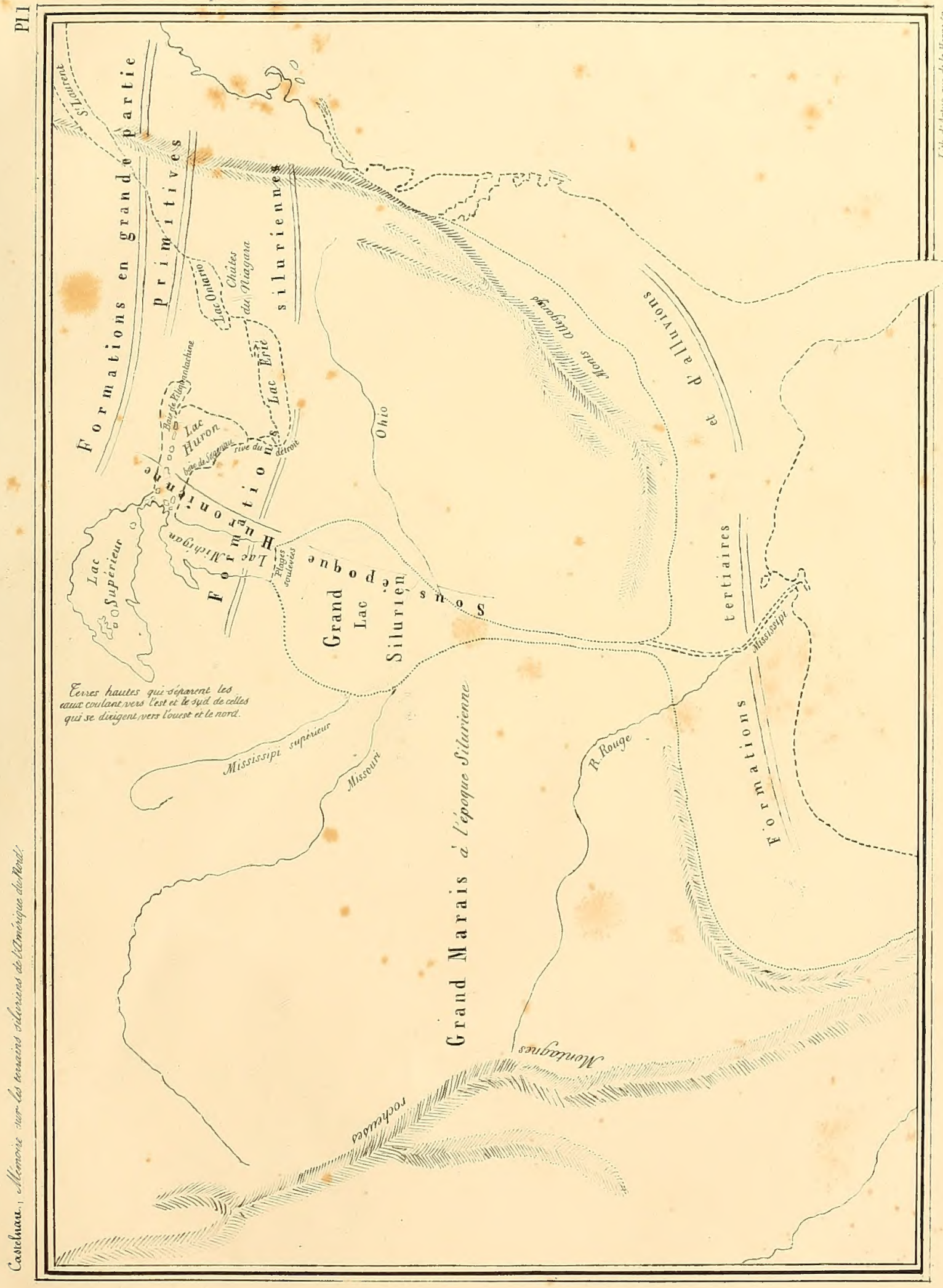




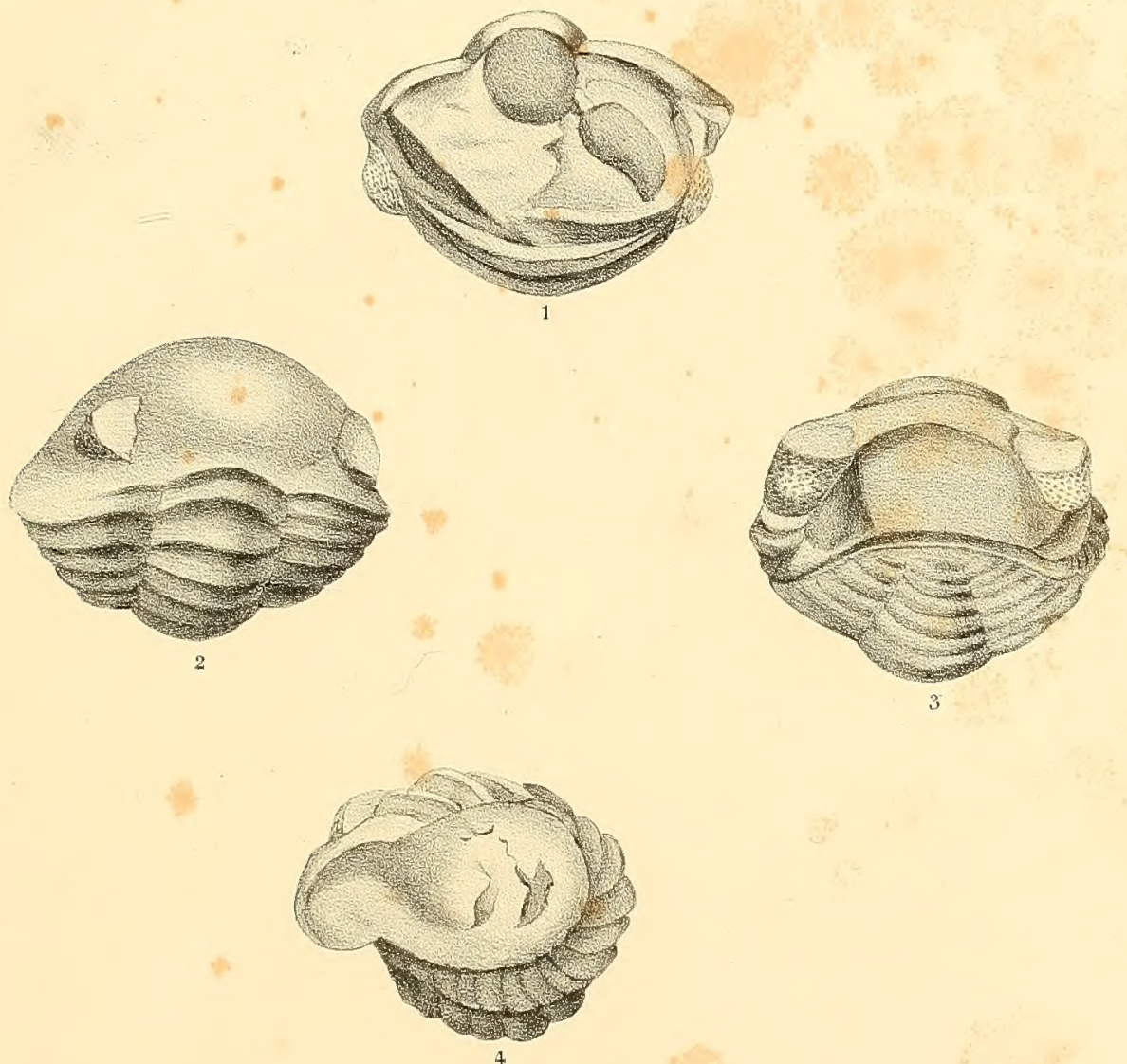

4

Lith. d'Artus, rue de la Harpe. 50

\section{Calyurue Brufo. Green.}

1. Soction die conps en bavers montrant une frate

2. liven dessins

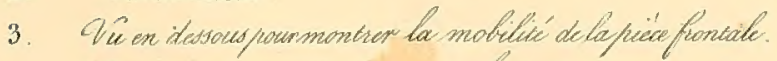

4. Vu de cótejeccion four montrer-les pattes. 



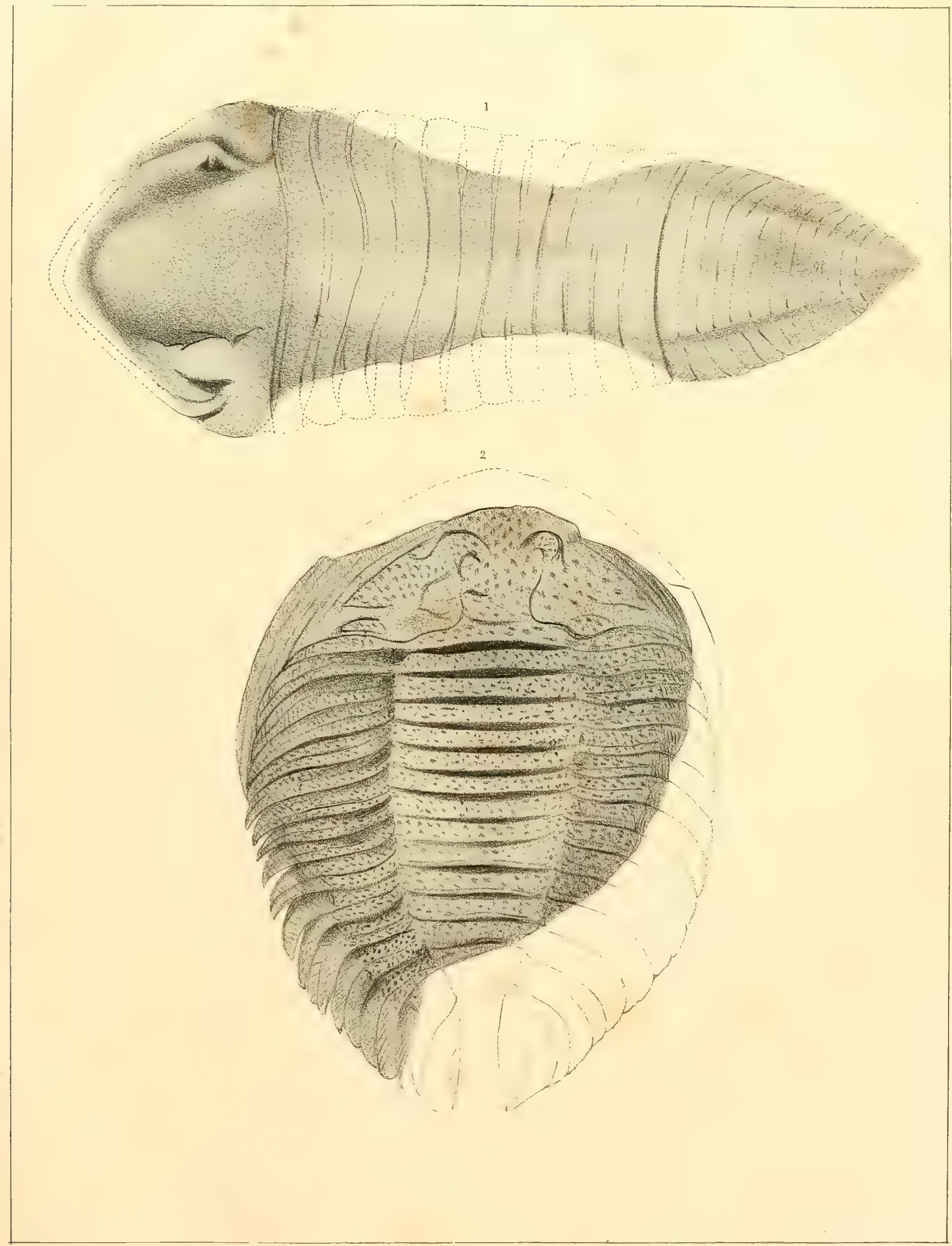

Lith. d'Artus rue de la Harpe so

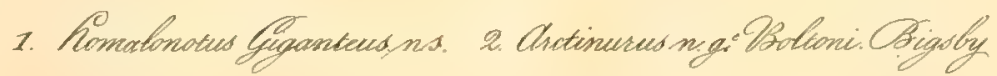


$M C E L$

HARVARD LI VI. $\cdots$. .

CAMBRIDGE. MA U 

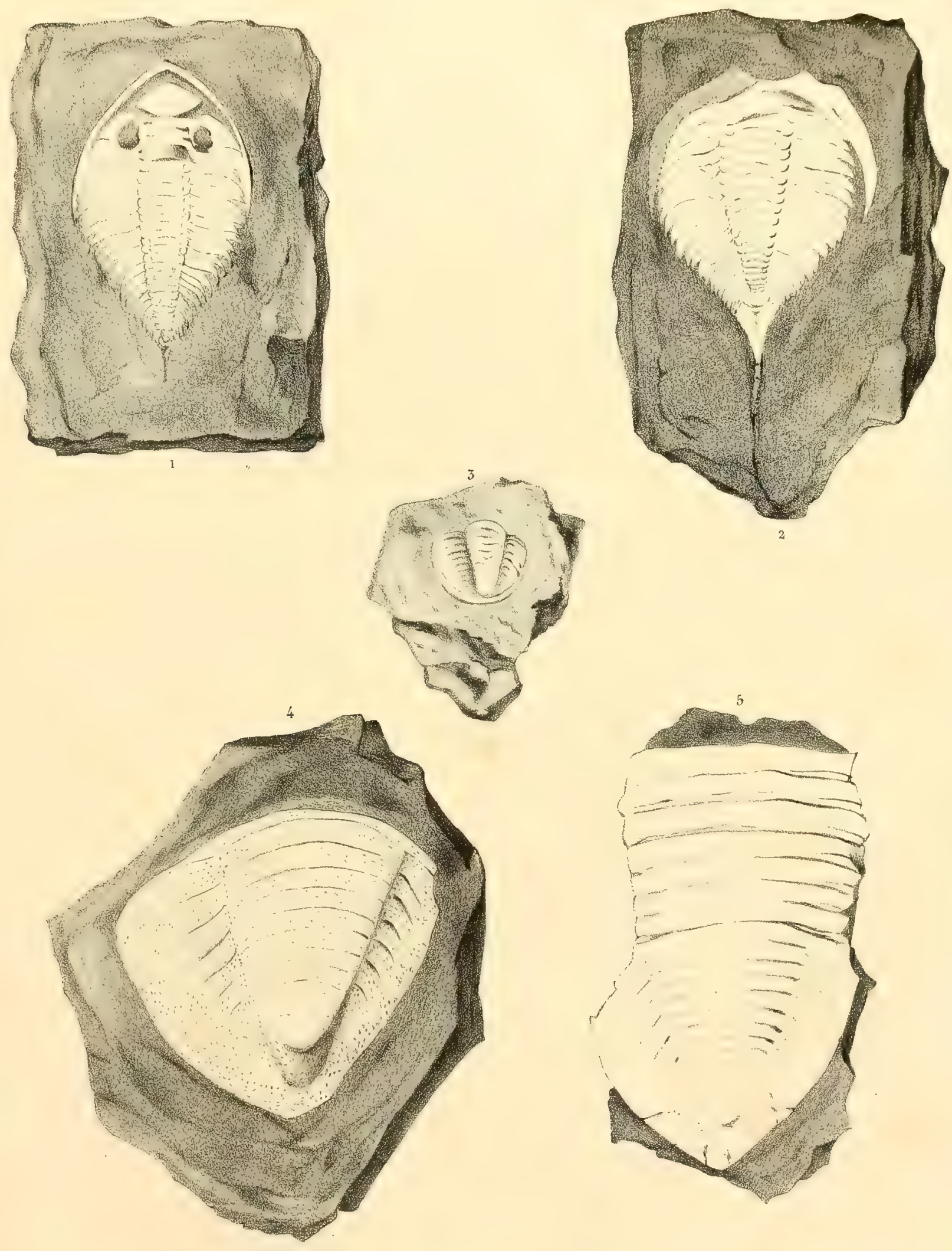

1. Asaphus Simularies, Green 4. Abomalonotud. Atlas n.

Lith A A the nue de To 耳aste 50 


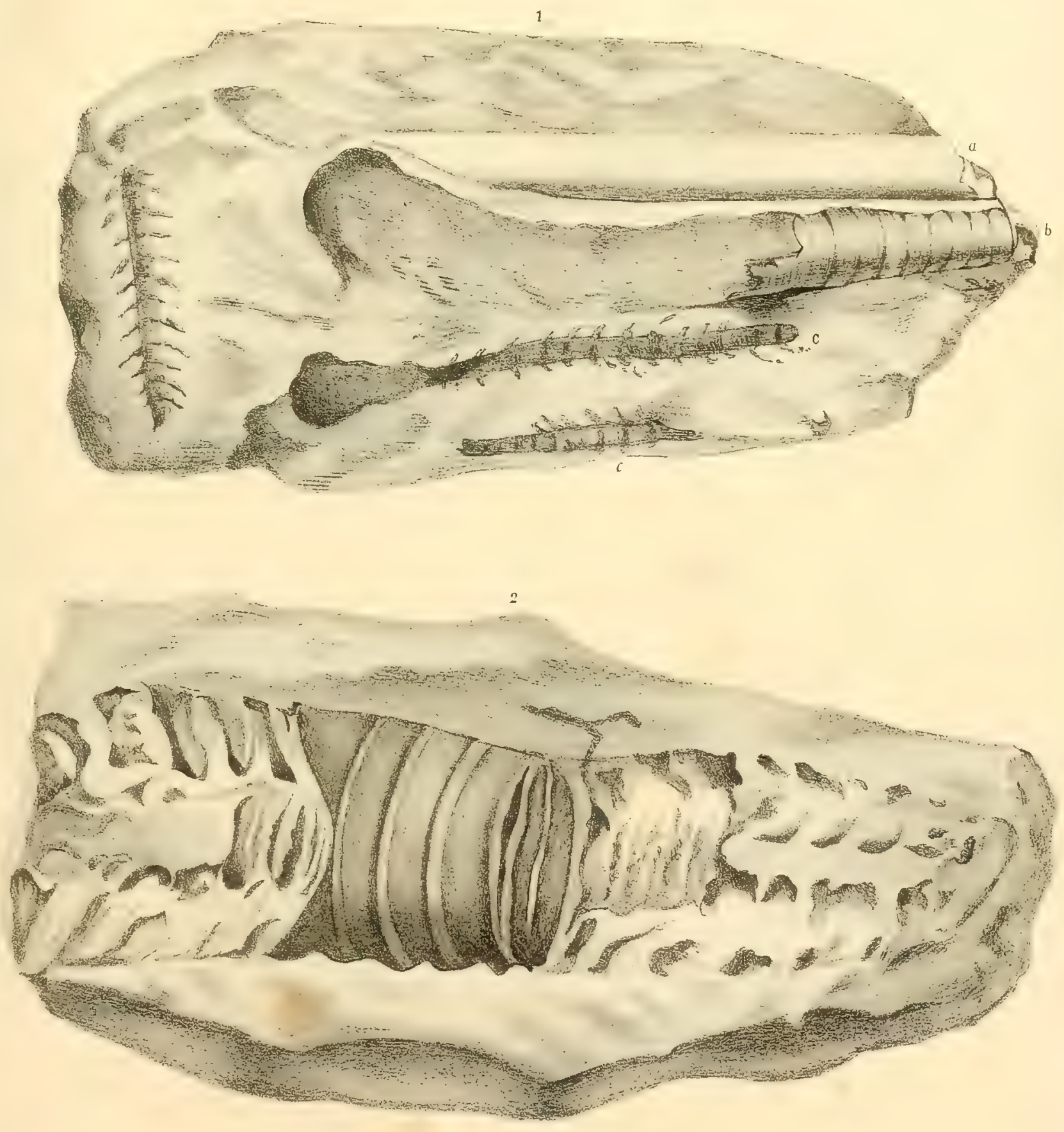

Iith. d'Artus, rue de la llarpe 50.

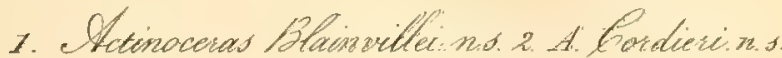





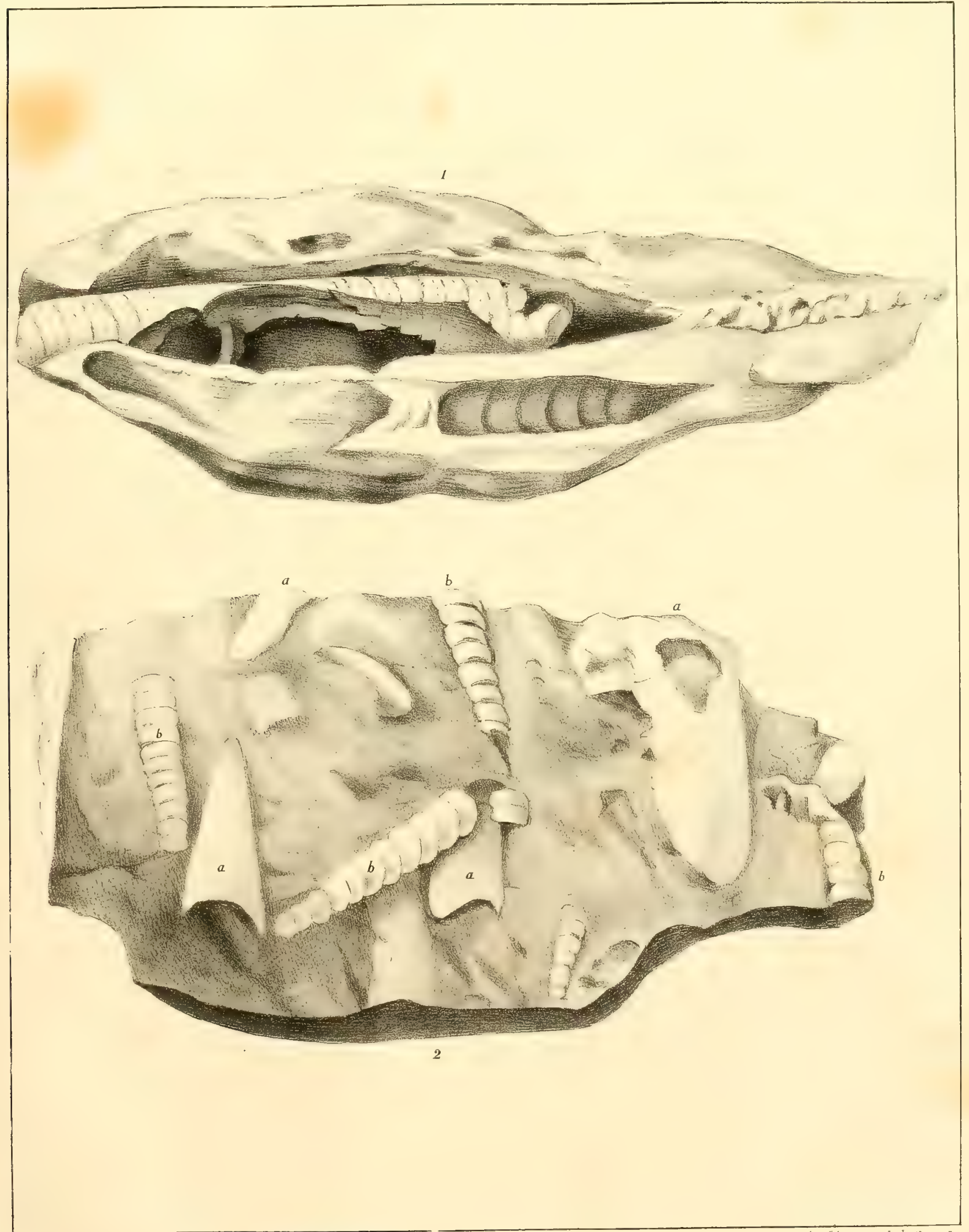


HART UIV UTY 


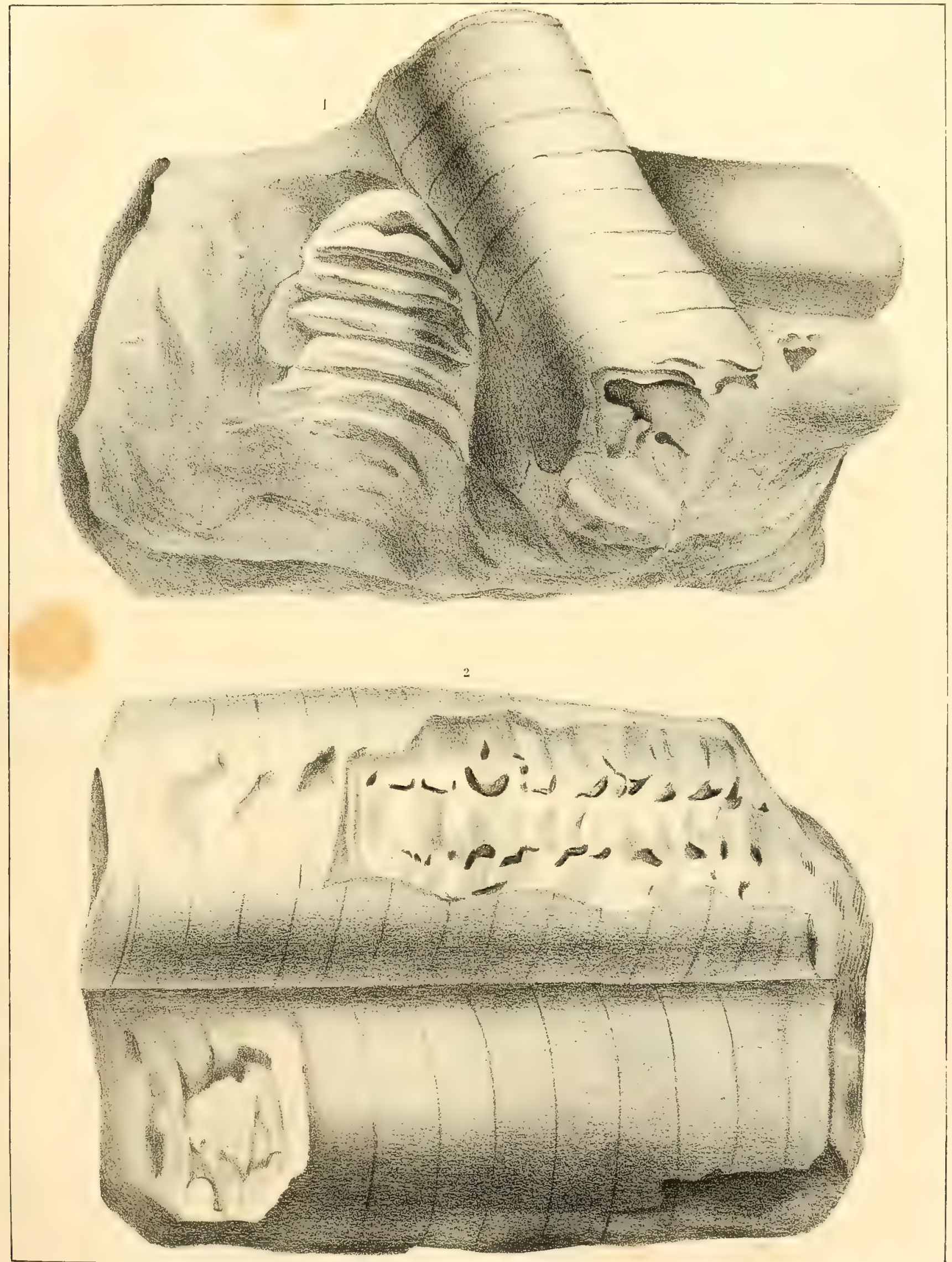

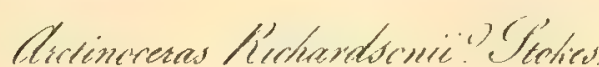





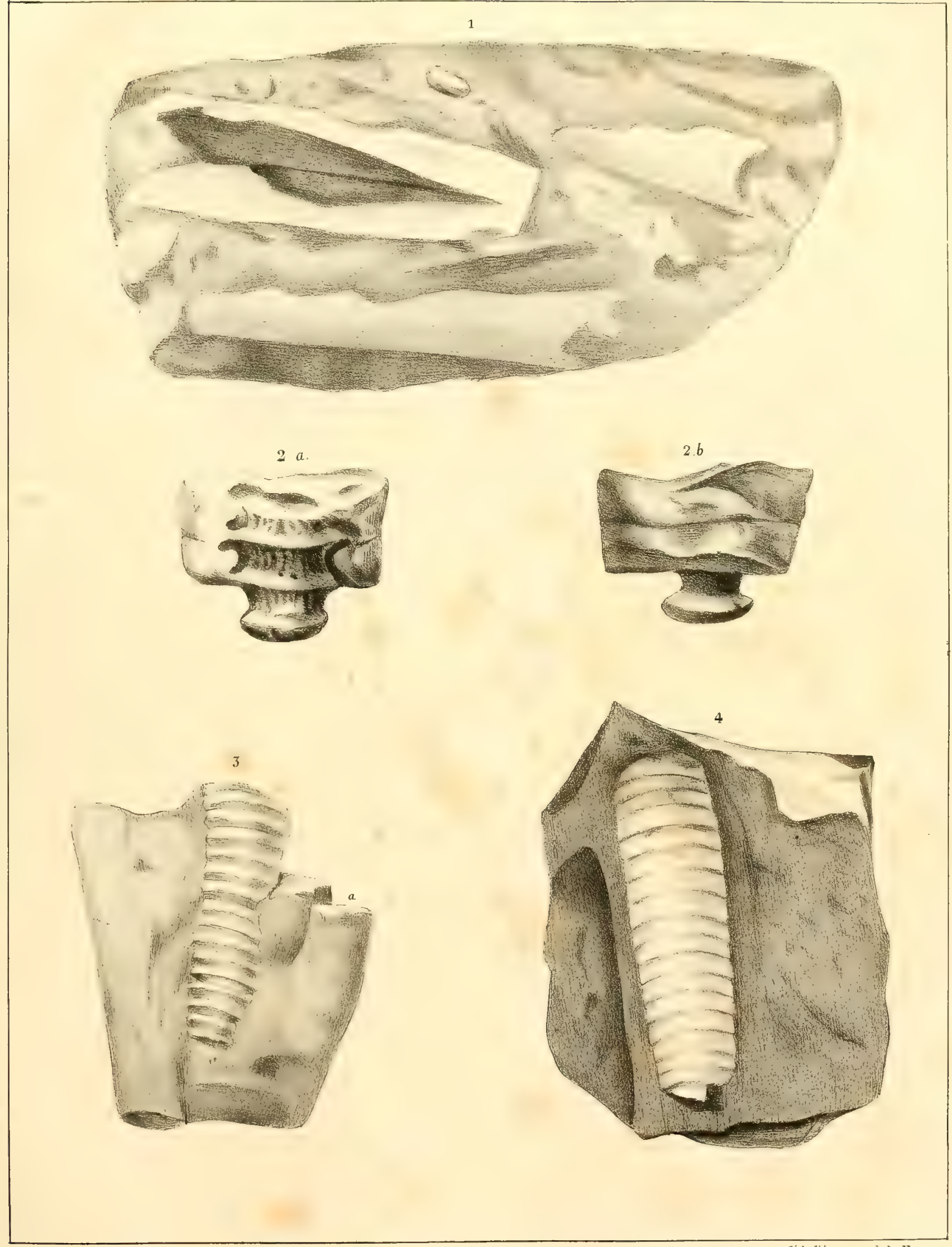

Actisneretert.

Lith.d'Artus, rue de la Harpe 50

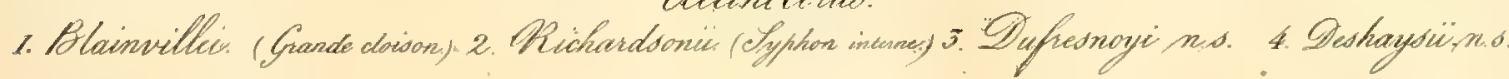





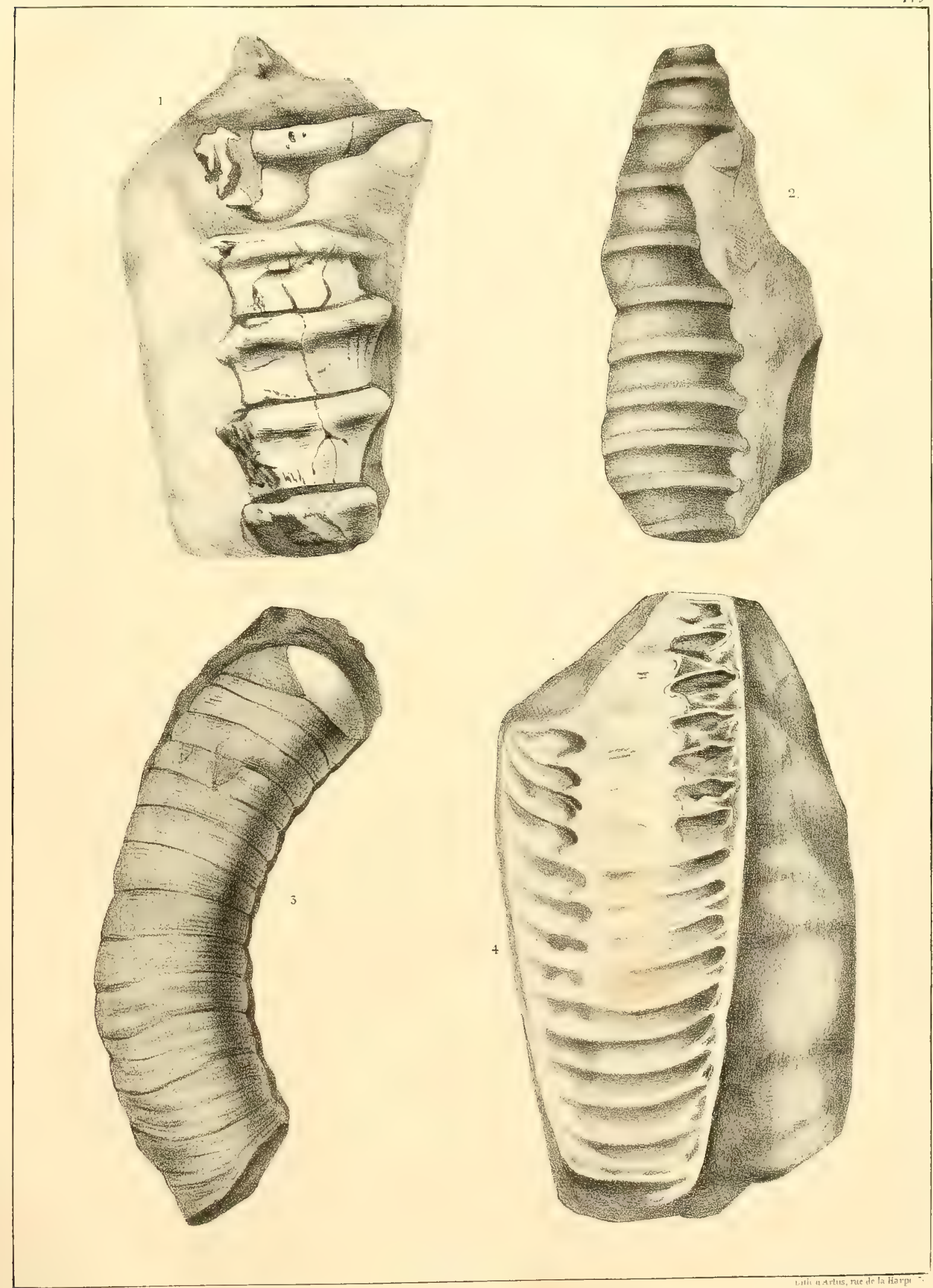

1. Rueronia obligurae n.s.

3. Coprocicas Mantioci, n.s.

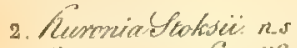

4. Actinoceras byonie" Jtoters. 



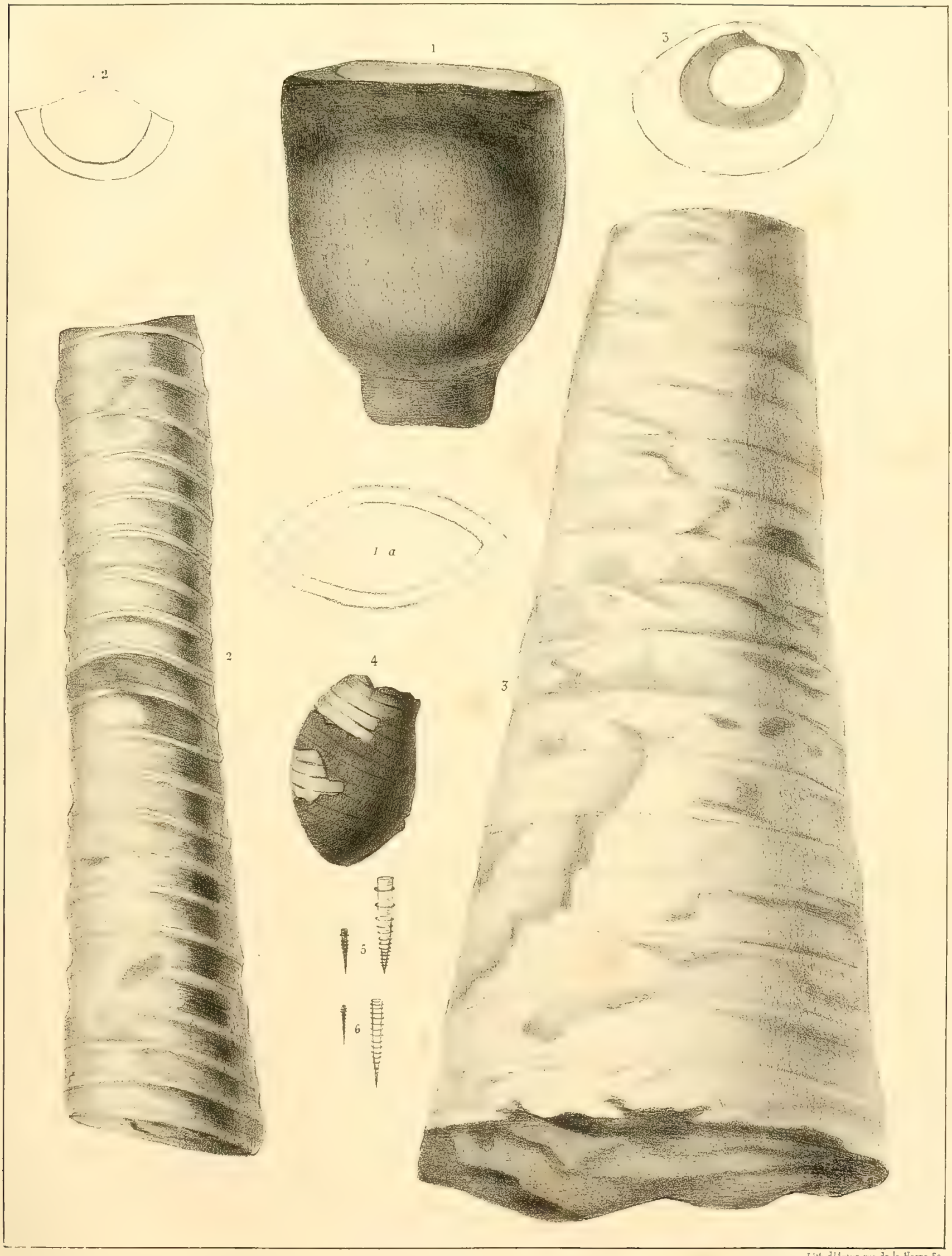

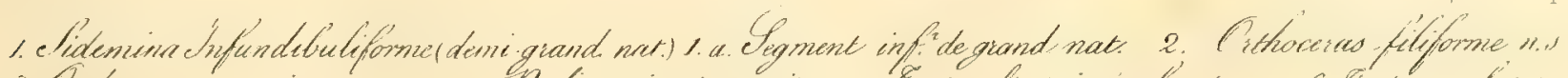

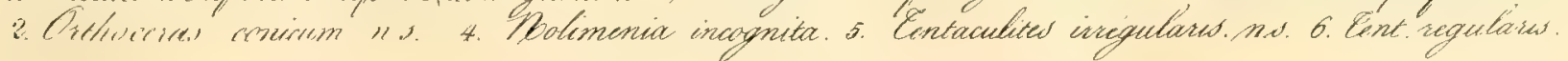




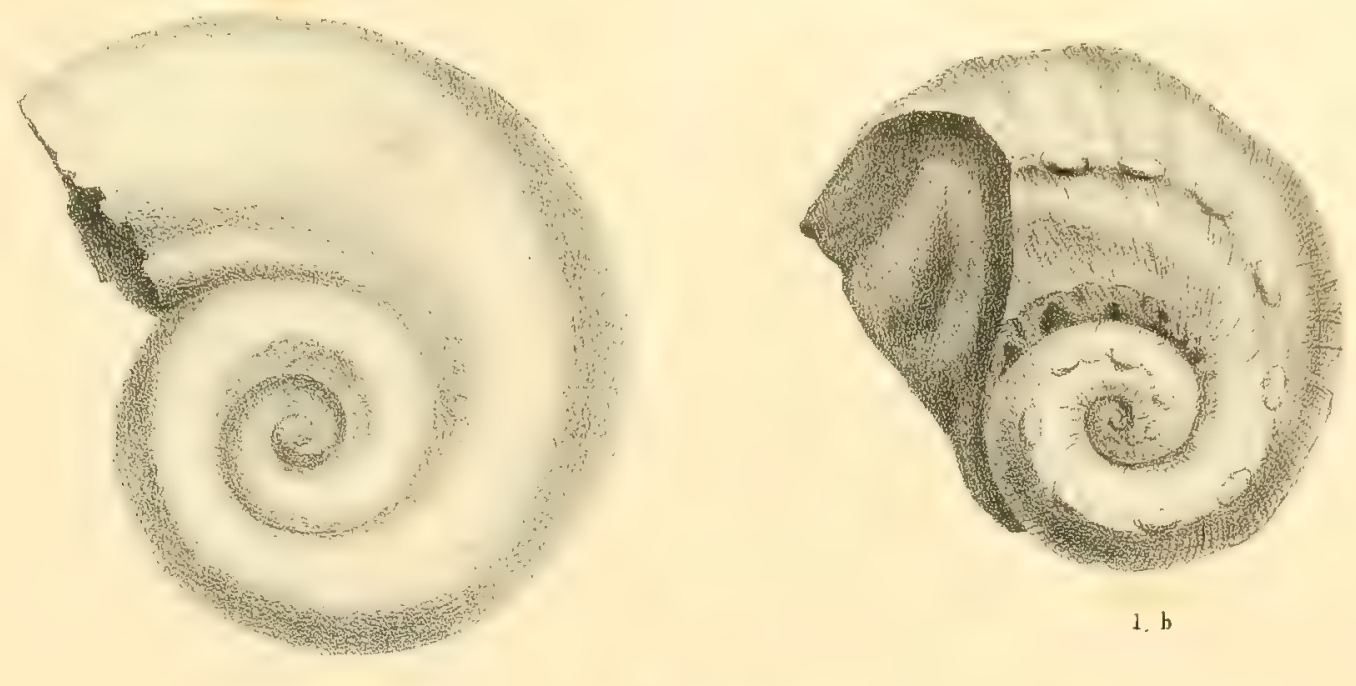

1. b
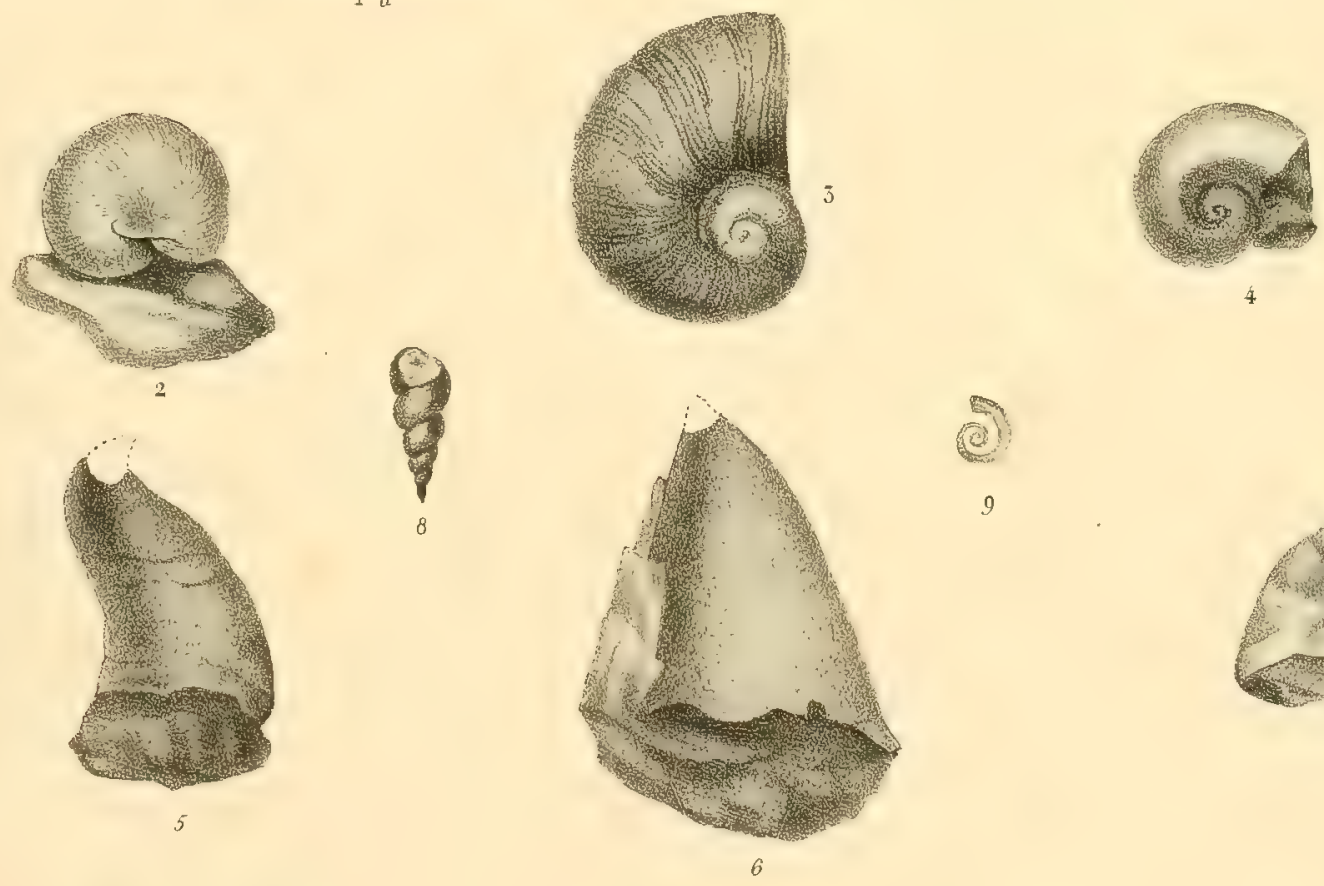

(c)

9
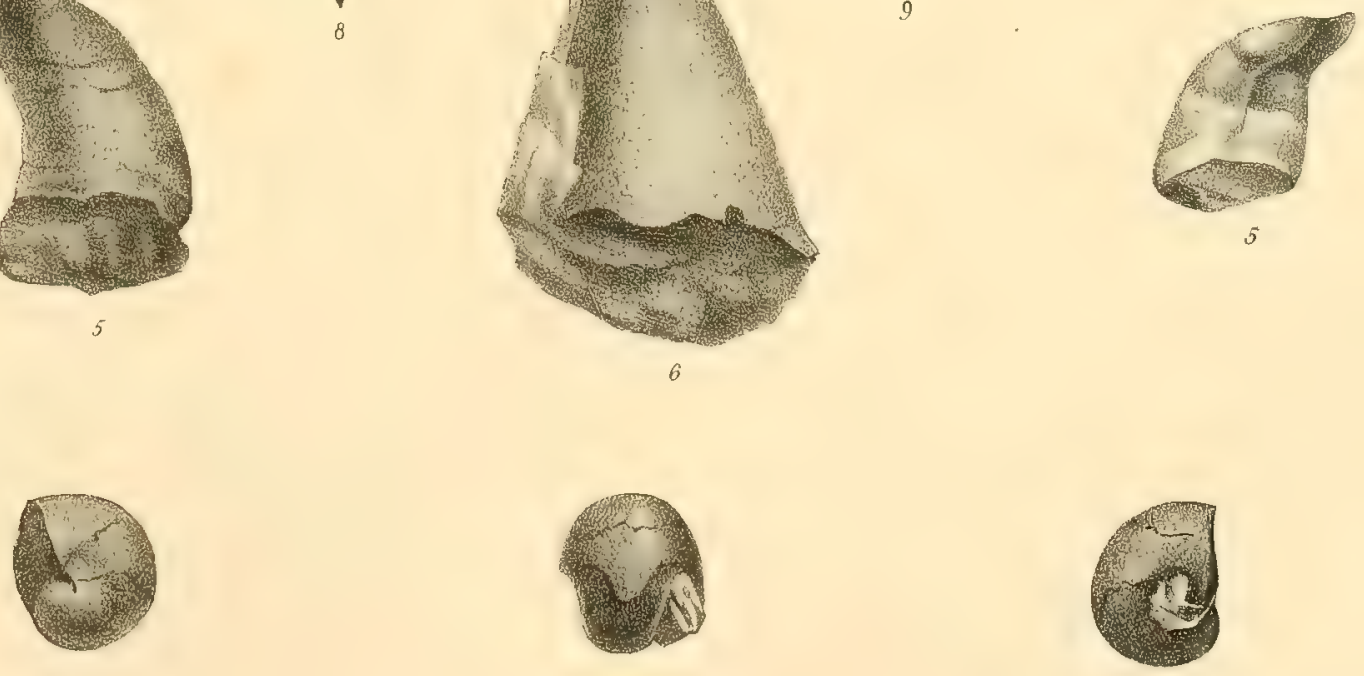

7

?

7

Lith d'Artuss, rue de la Farpe 5o.

7. Guomphalus Derneuillin: 4. Roundatar. nod.

7. Goniatis Canadensis ns.
2. Dellerithon Coriatus.

5. P. Phisalis nos.

8. Turritella tchohariensid nes.
I. Pileophis naticöles. ns.

6. Pilcopisis conoides nus.

Q. Cicompinalus minutistimus ns. grossi 8 fois.) 



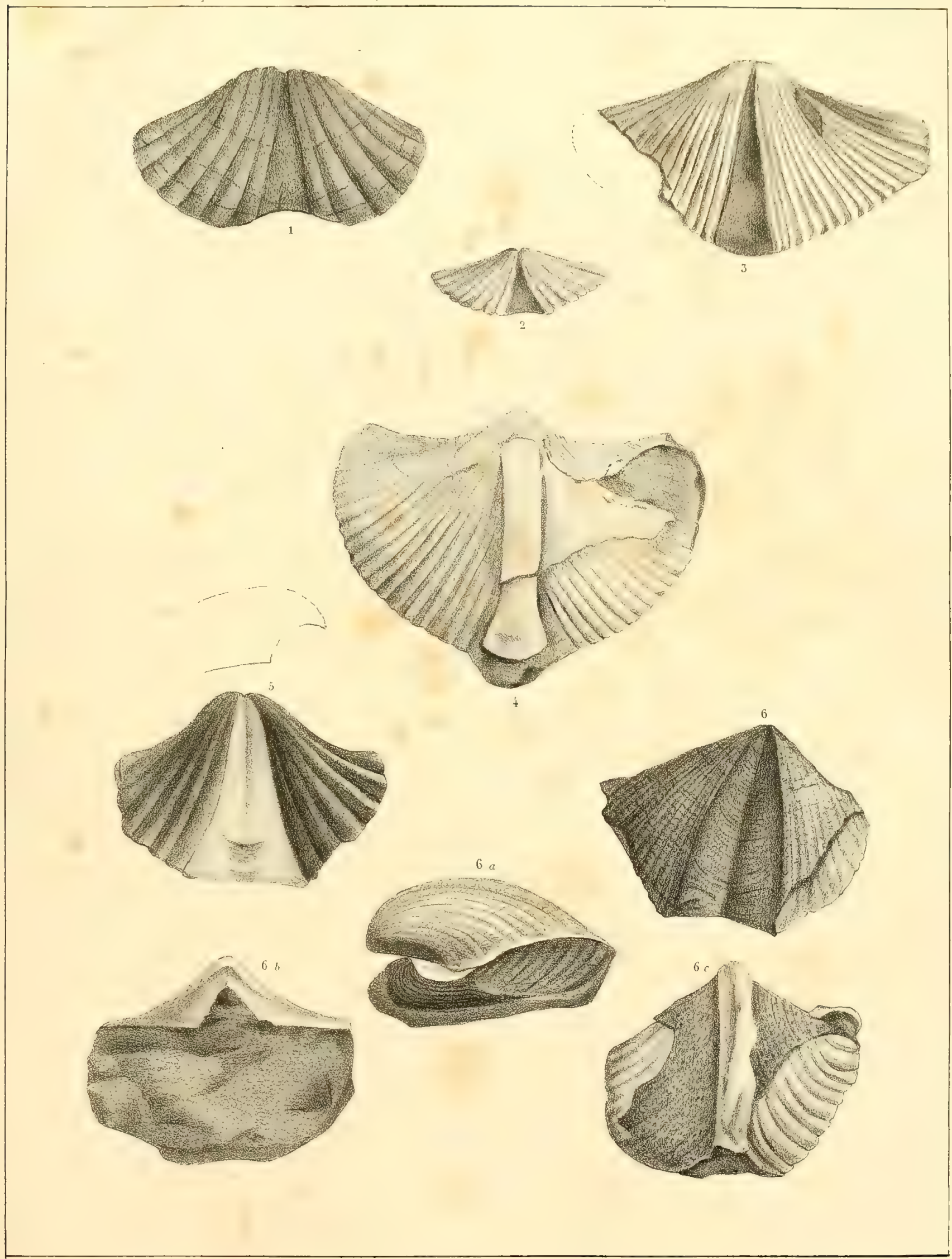

Lith. d'Artus, rue de la सarpe. bo
1. Shiefer Nuchisoni, ns.

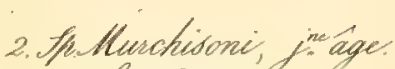
2. S. Luticostatus. nos.
2 He ctlatus. n.s
5. efr. broosici.
6. Th huroniensio. no. 


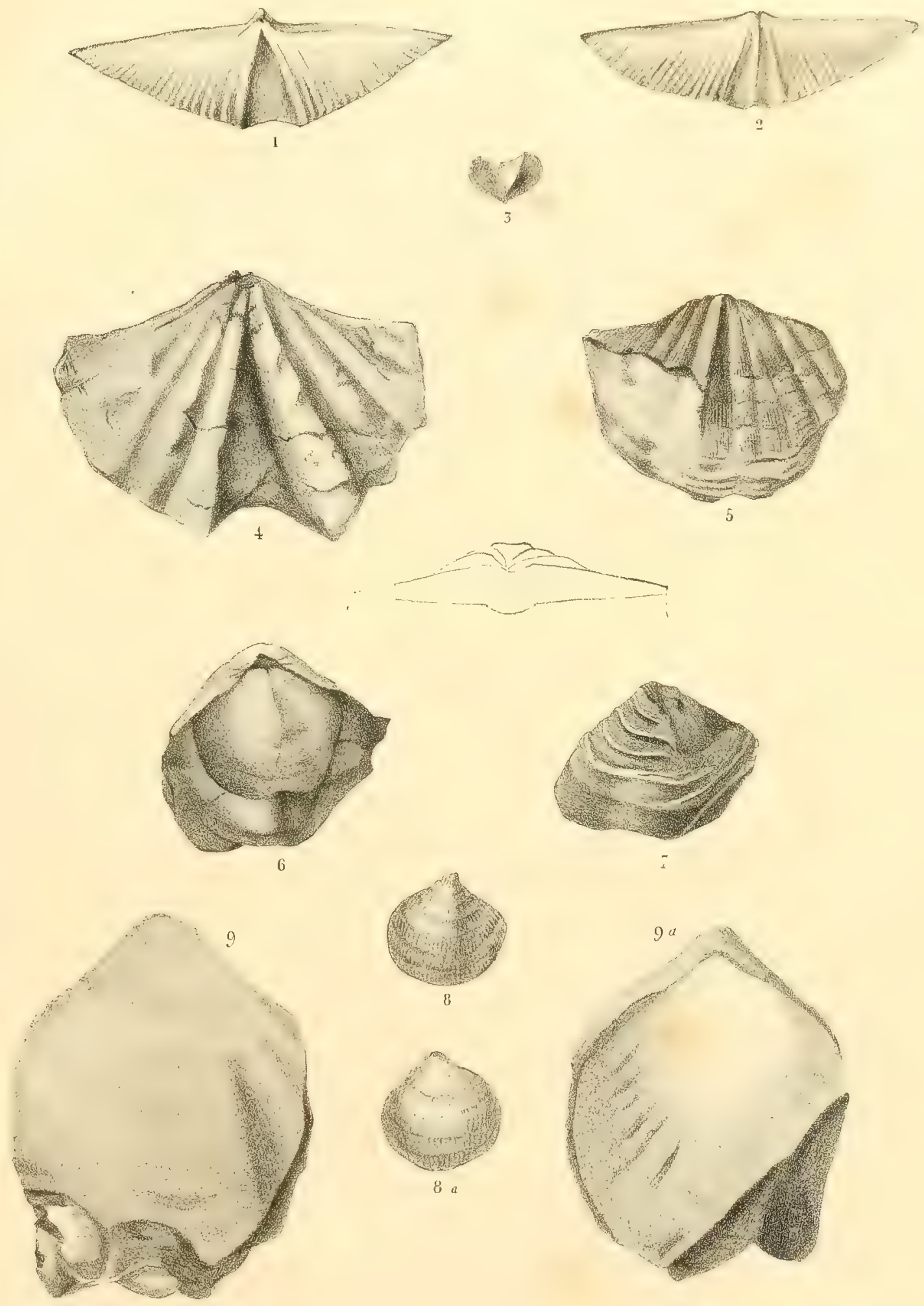

Lith deArtus, rue de la Harpe's

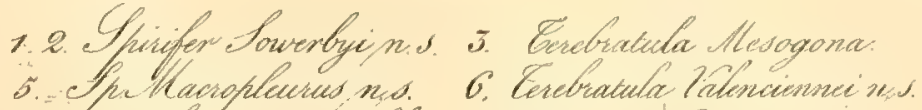

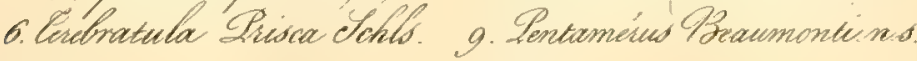

4. Shivifer efischaisno.

- Eprodectud lietcatres. nis 


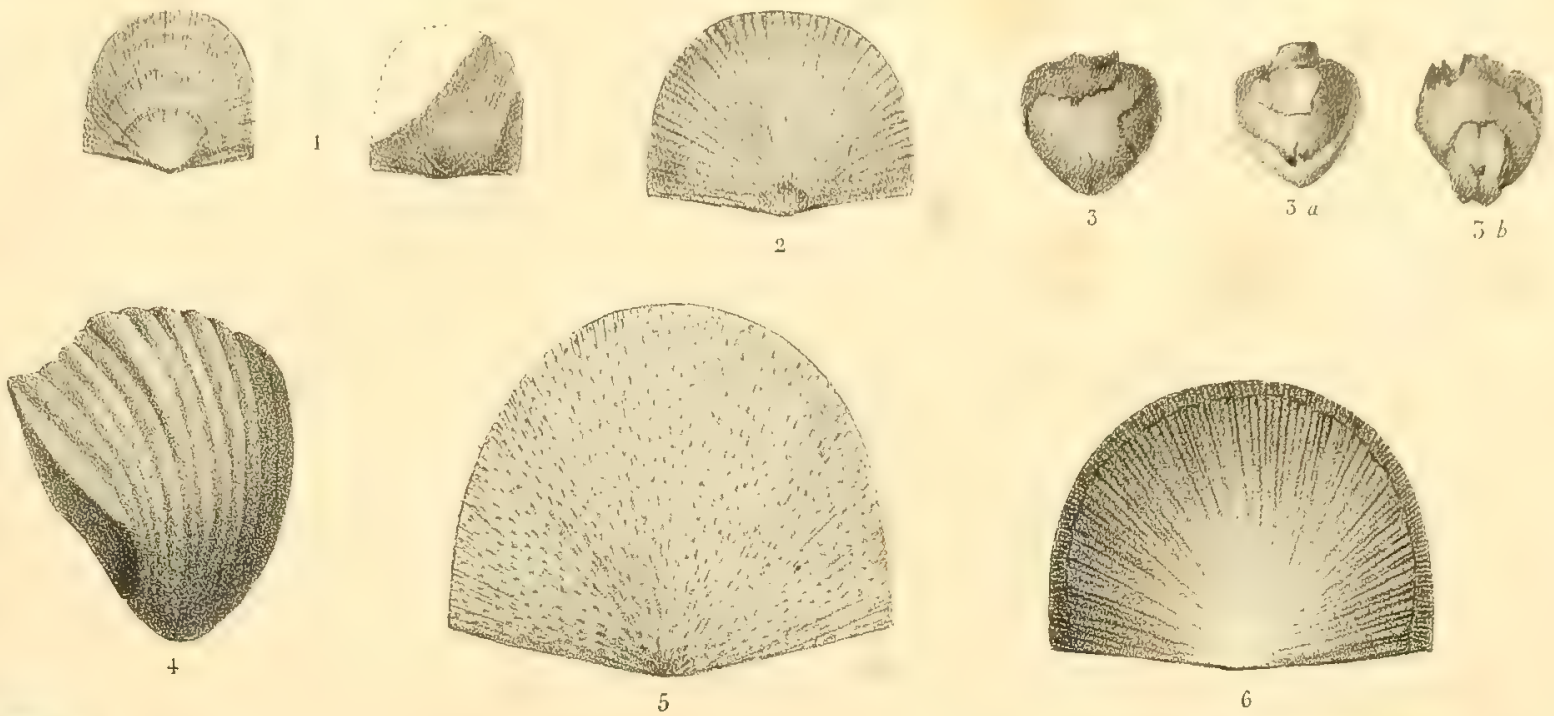

Wh
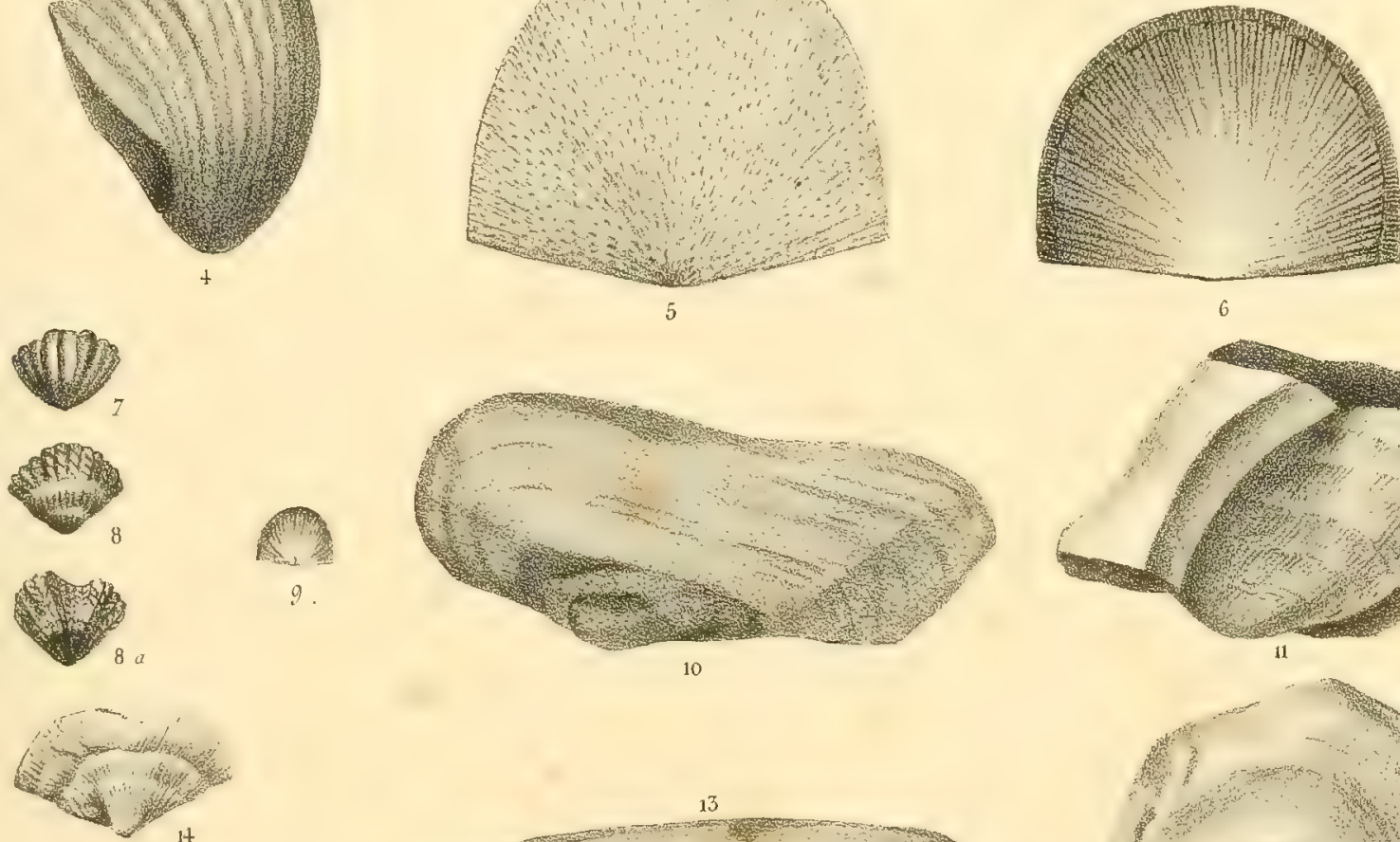

10
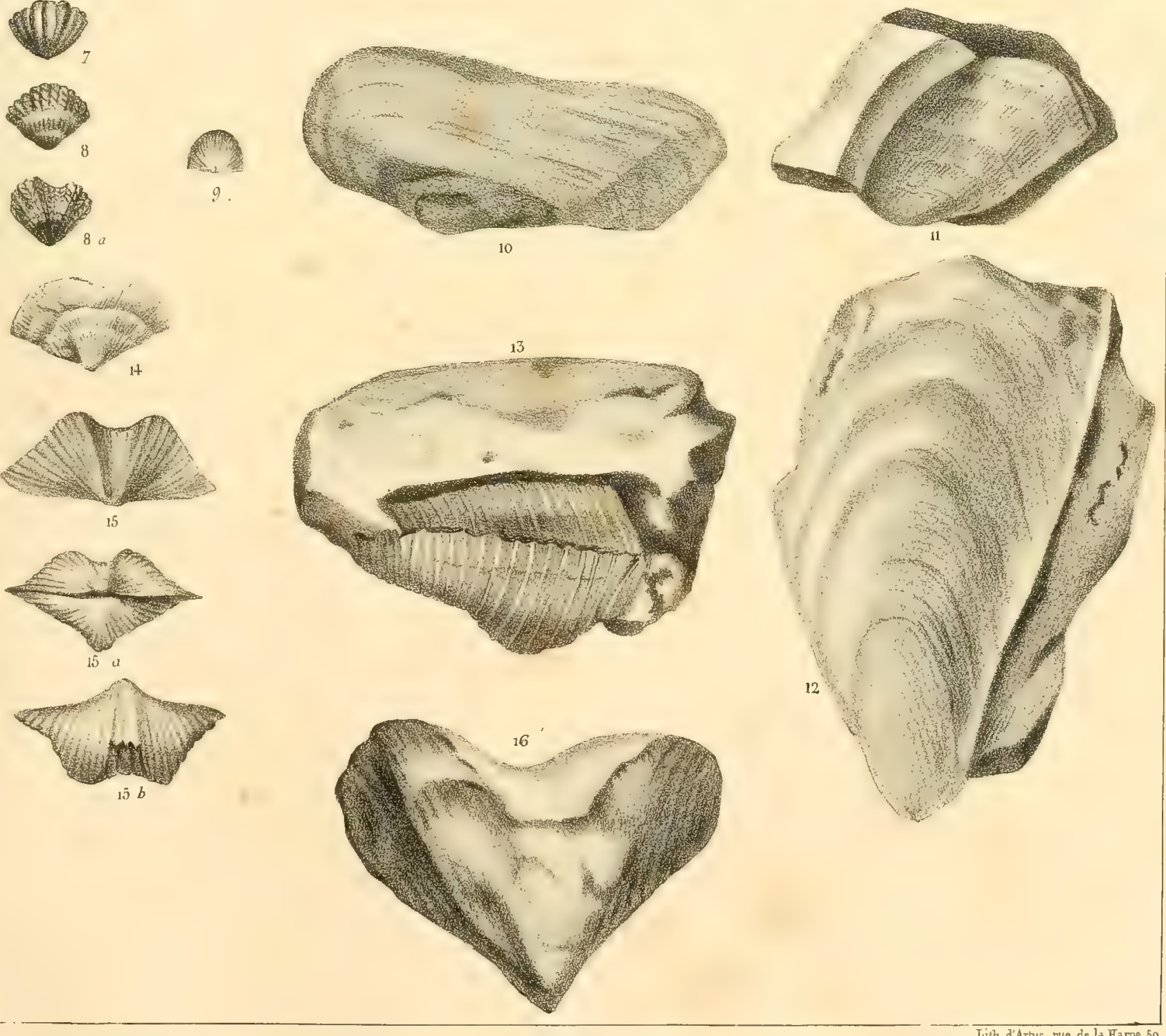

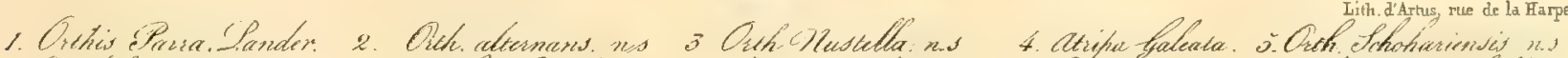

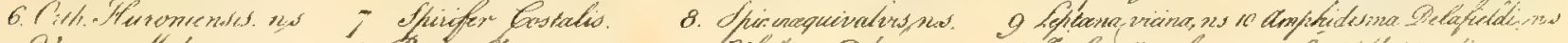

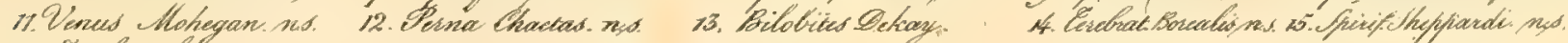
16. Eerebratula acuminatissina. 



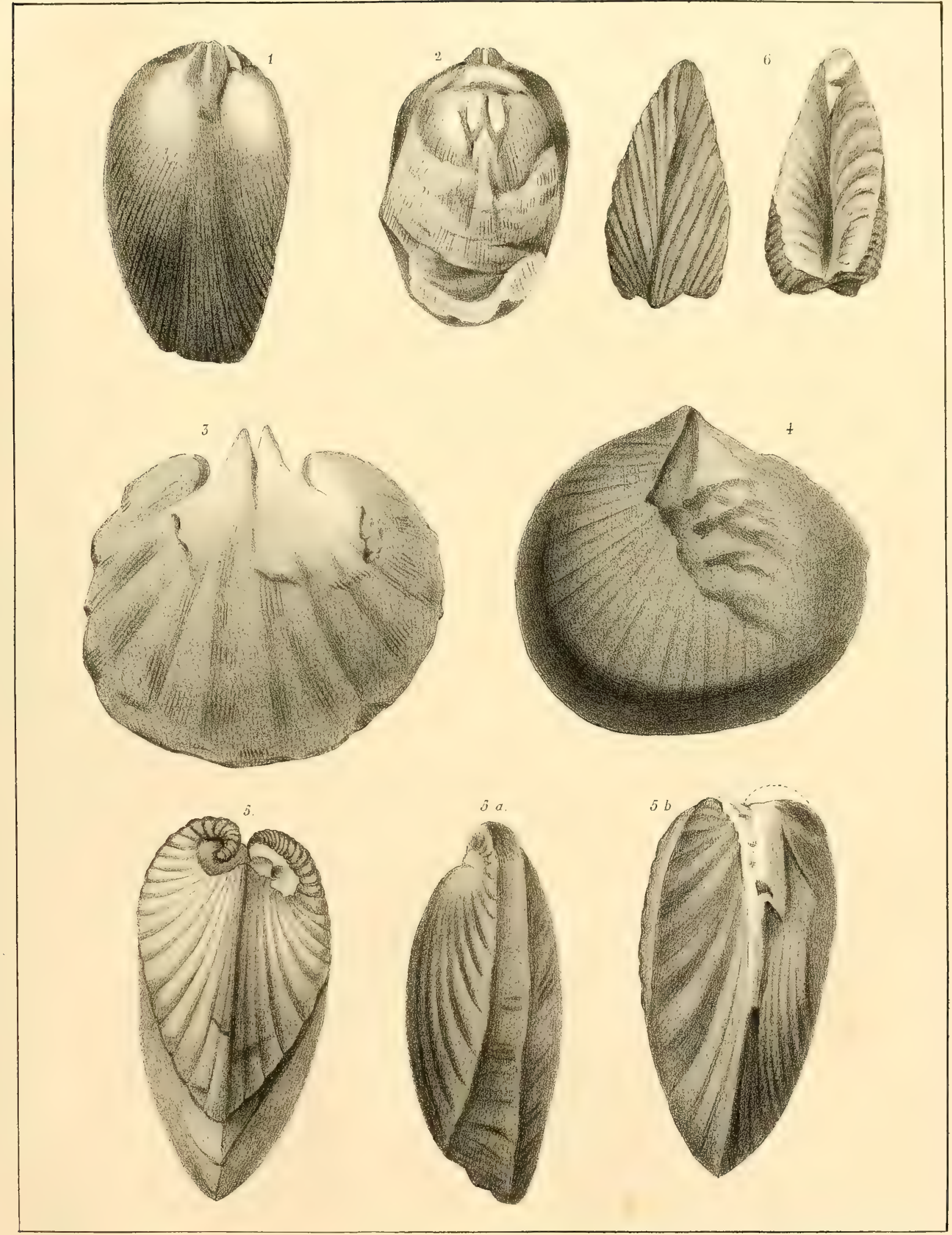

Lith d'Artus, Tue de la Harpe.

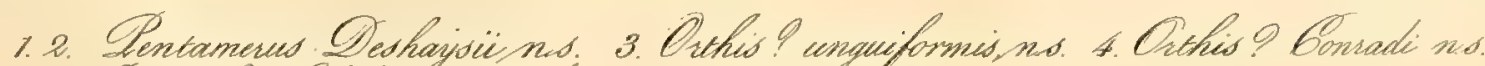

o. Cardium? (Goldfusia) Mautibides nis. 6. id var. 


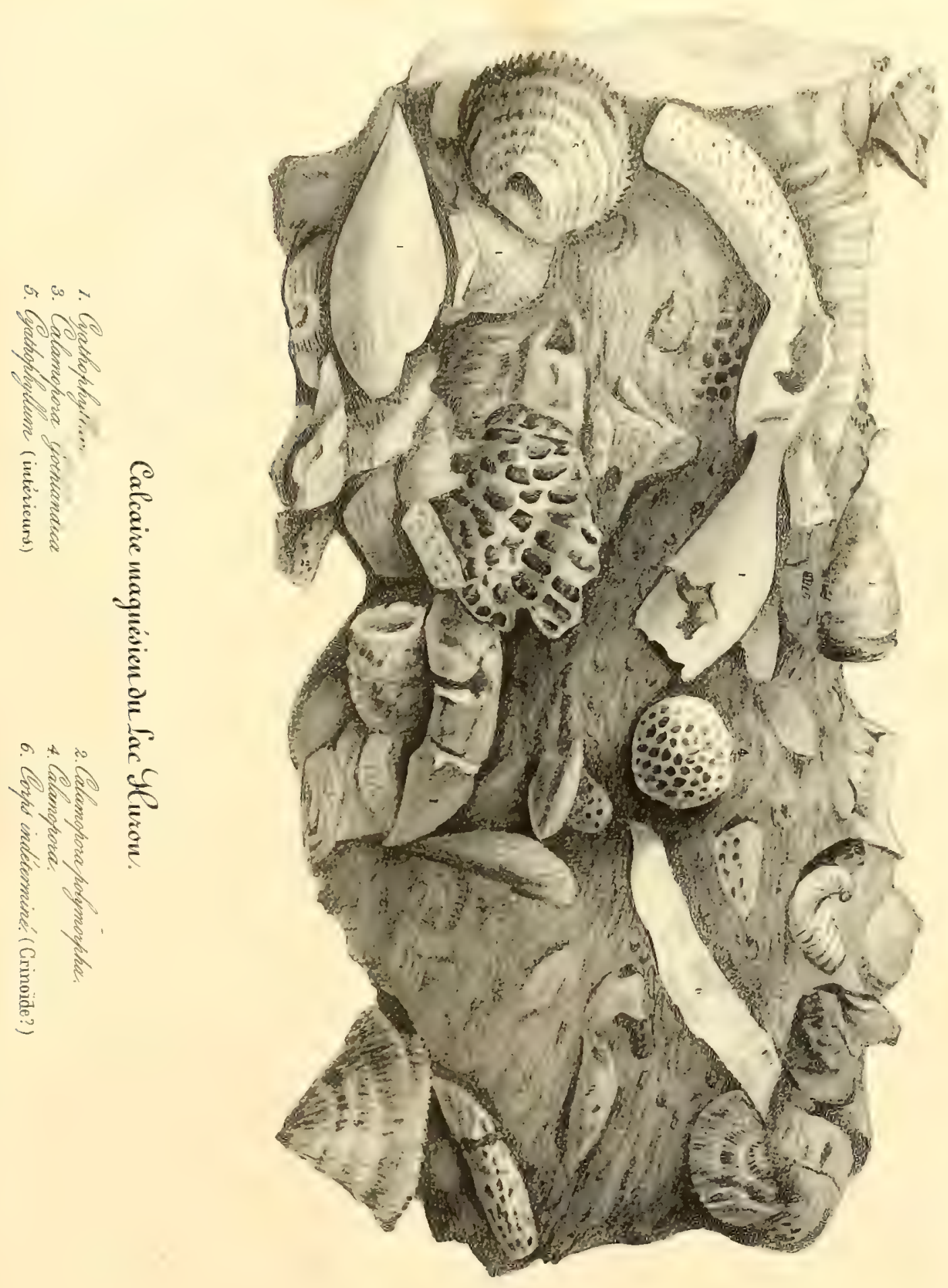

Lith d'Artus, rue de la Harpe, 50 
- - INTYY

L $=G$ WA USA 

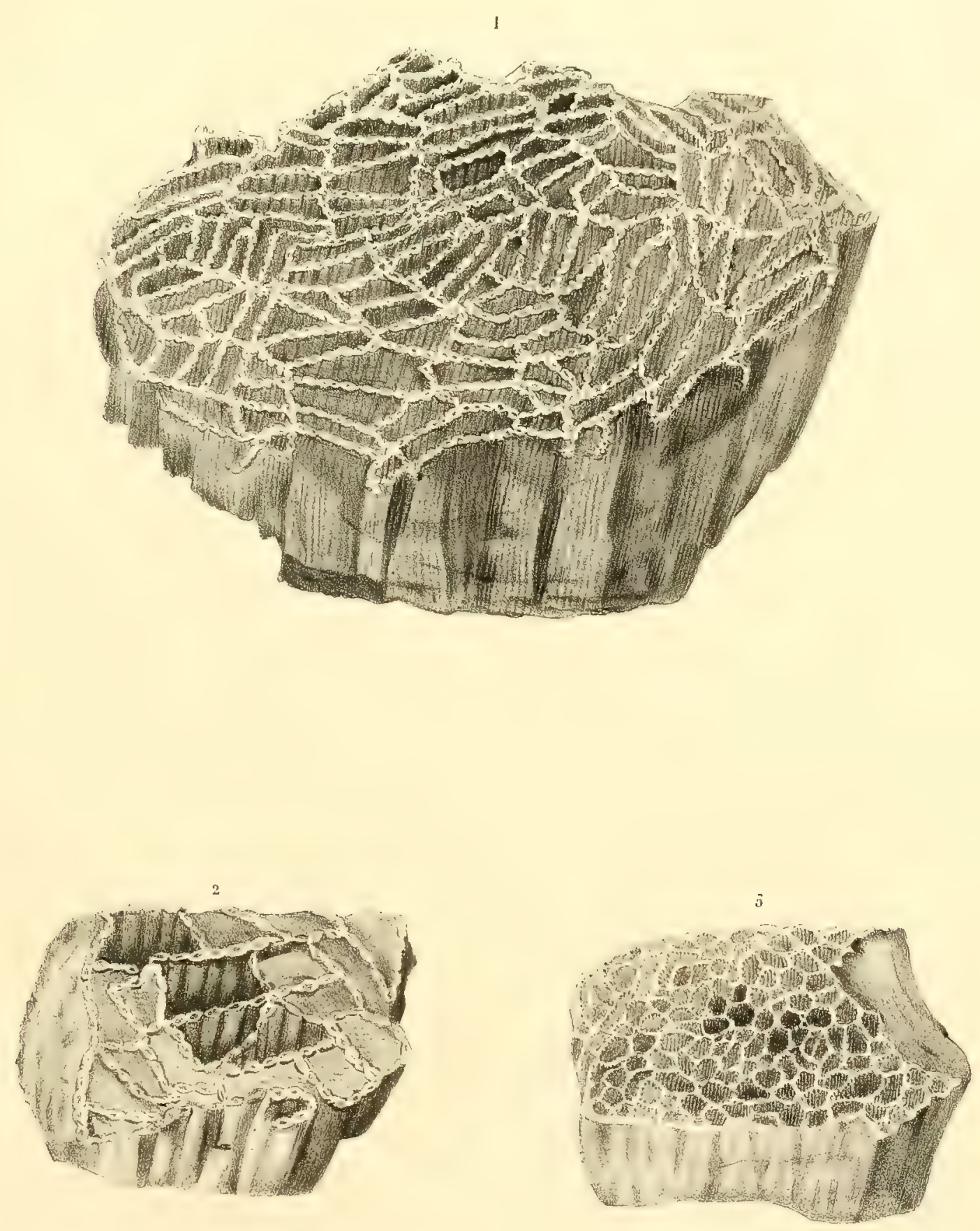

Tadencifora:

1. C. Wichelini ns. 2. O Sabyinthica 3.C. Gisharoided.

Lith. d'Artus rue de la Harpe, 50 
$-\quad-\quad . \quad 5$ 


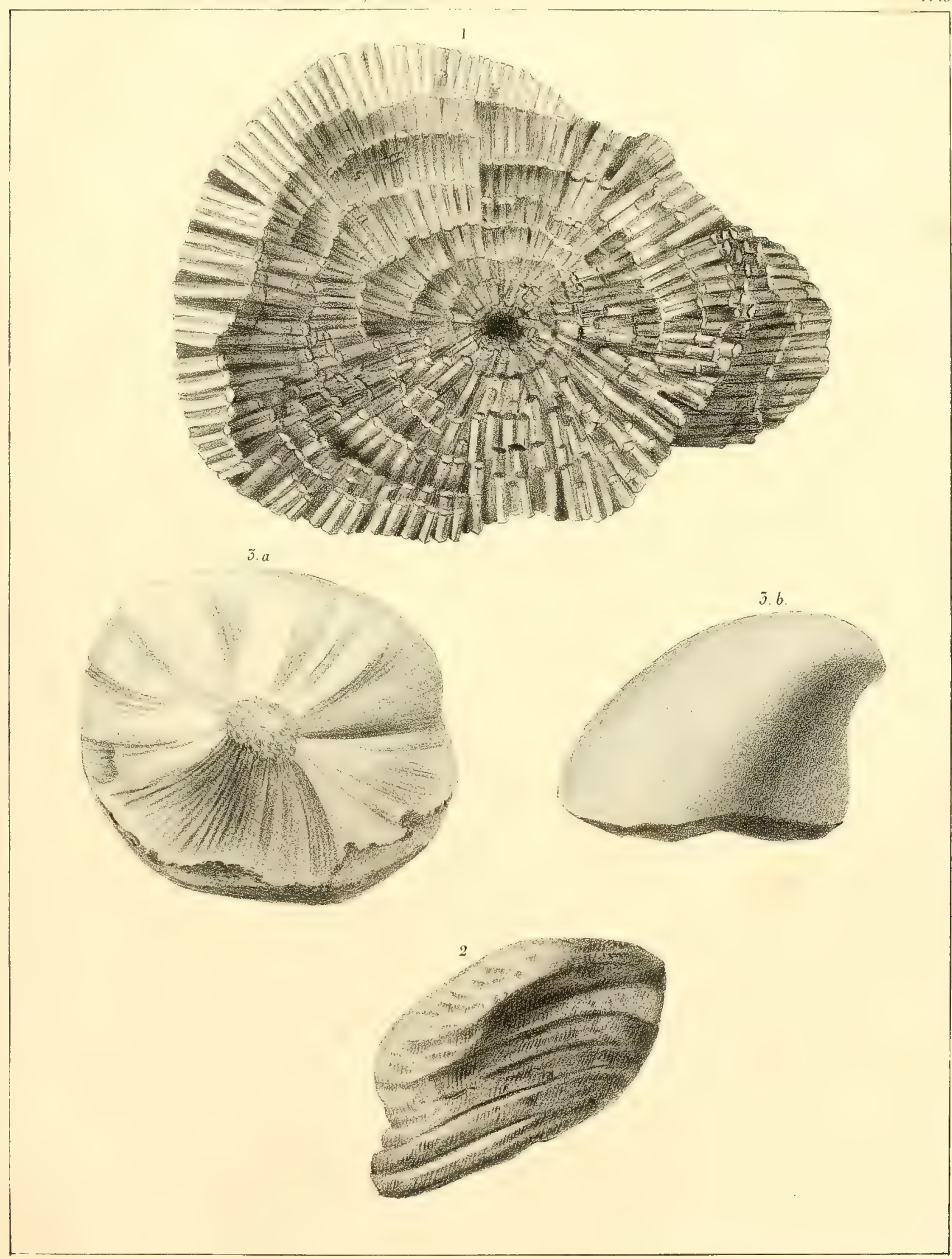

\section{Calamopore}

1.c. Radians, no. 2. c. Llimutissimas not. 3.c. Masaltica a in dessous. b. de coté. 


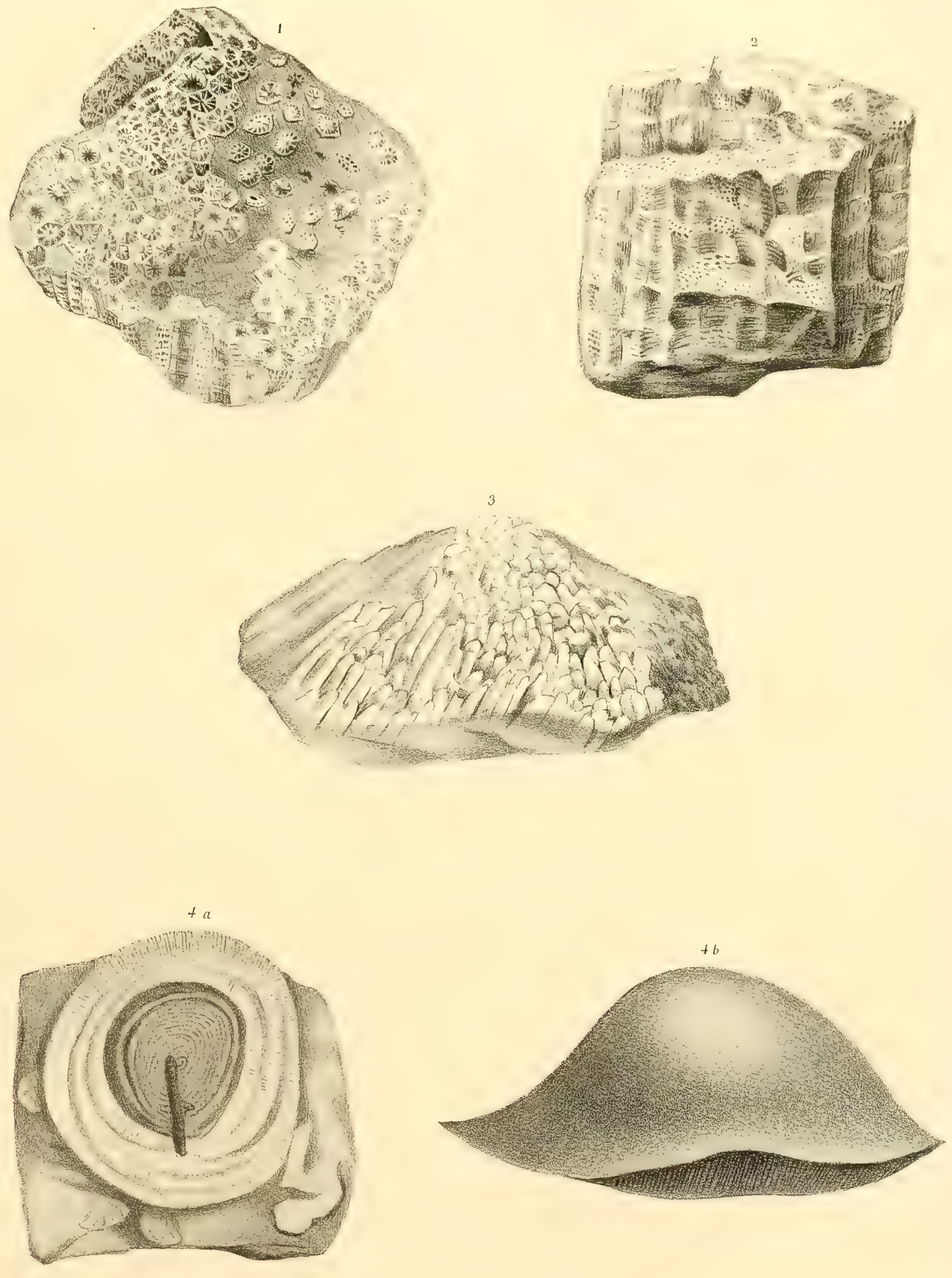

Golumnaria.

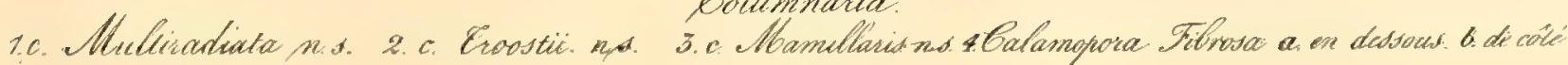




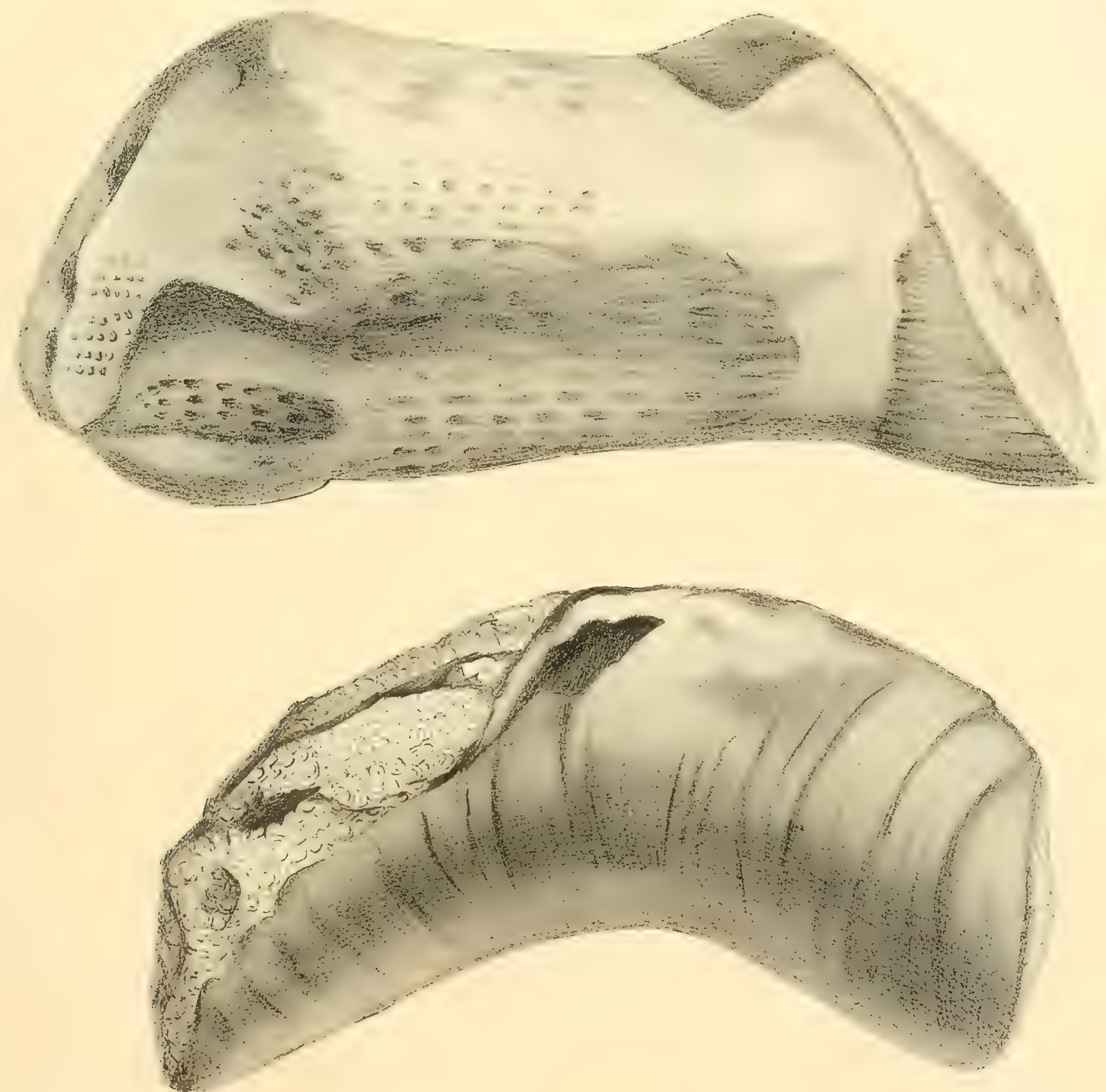

Lith a'Artus, rue de la Harpe 50

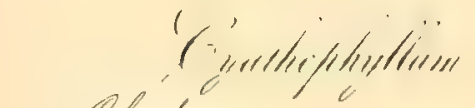

r. Goliathe nos. a a Alas nes 



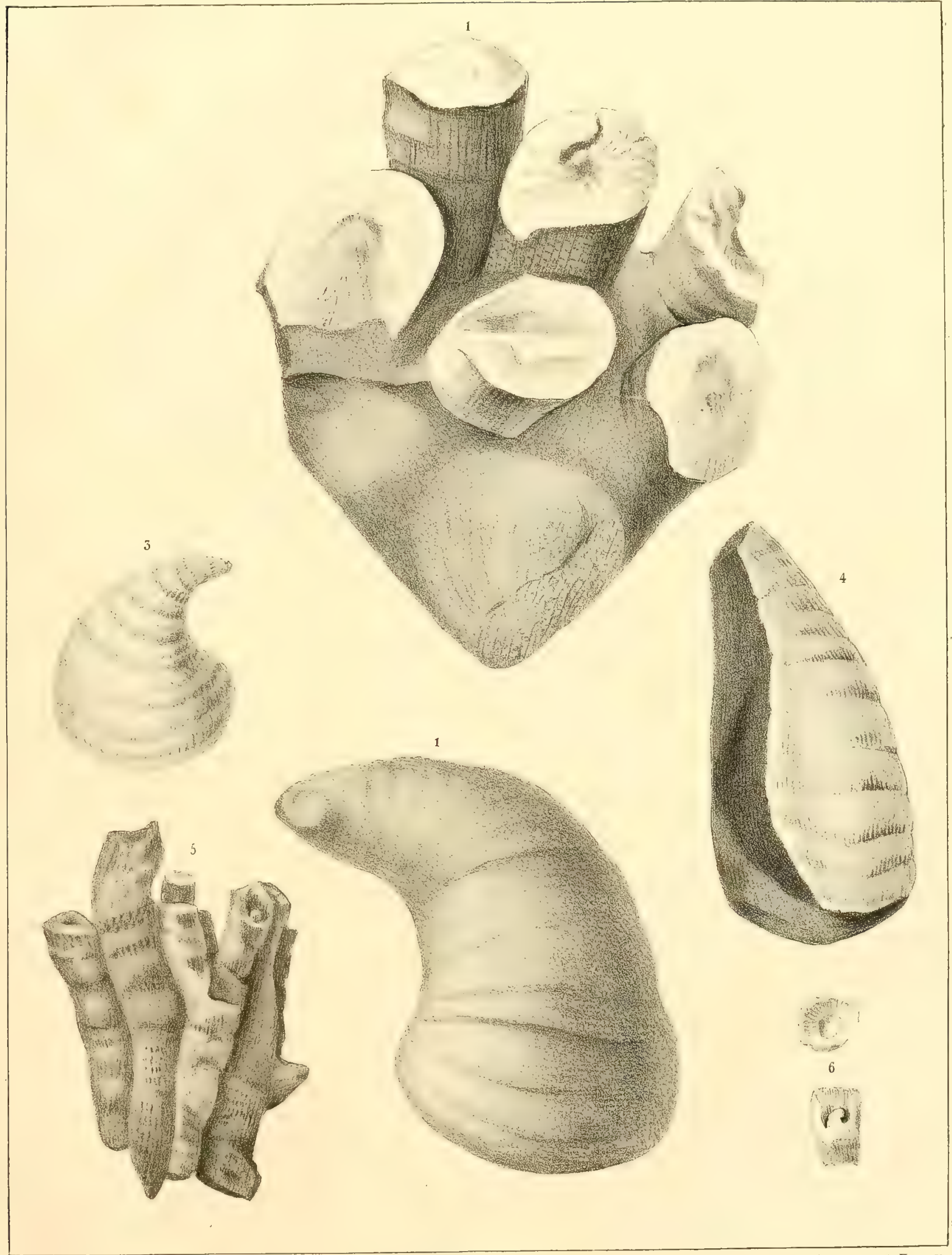

\section{Cyathophyllum.}

Lith. d'Artus rue de la Harpe 60

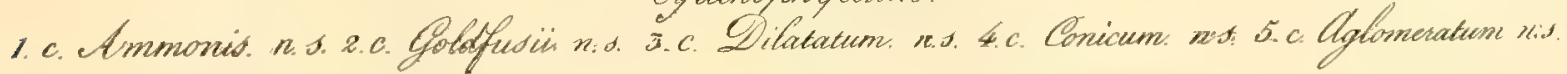





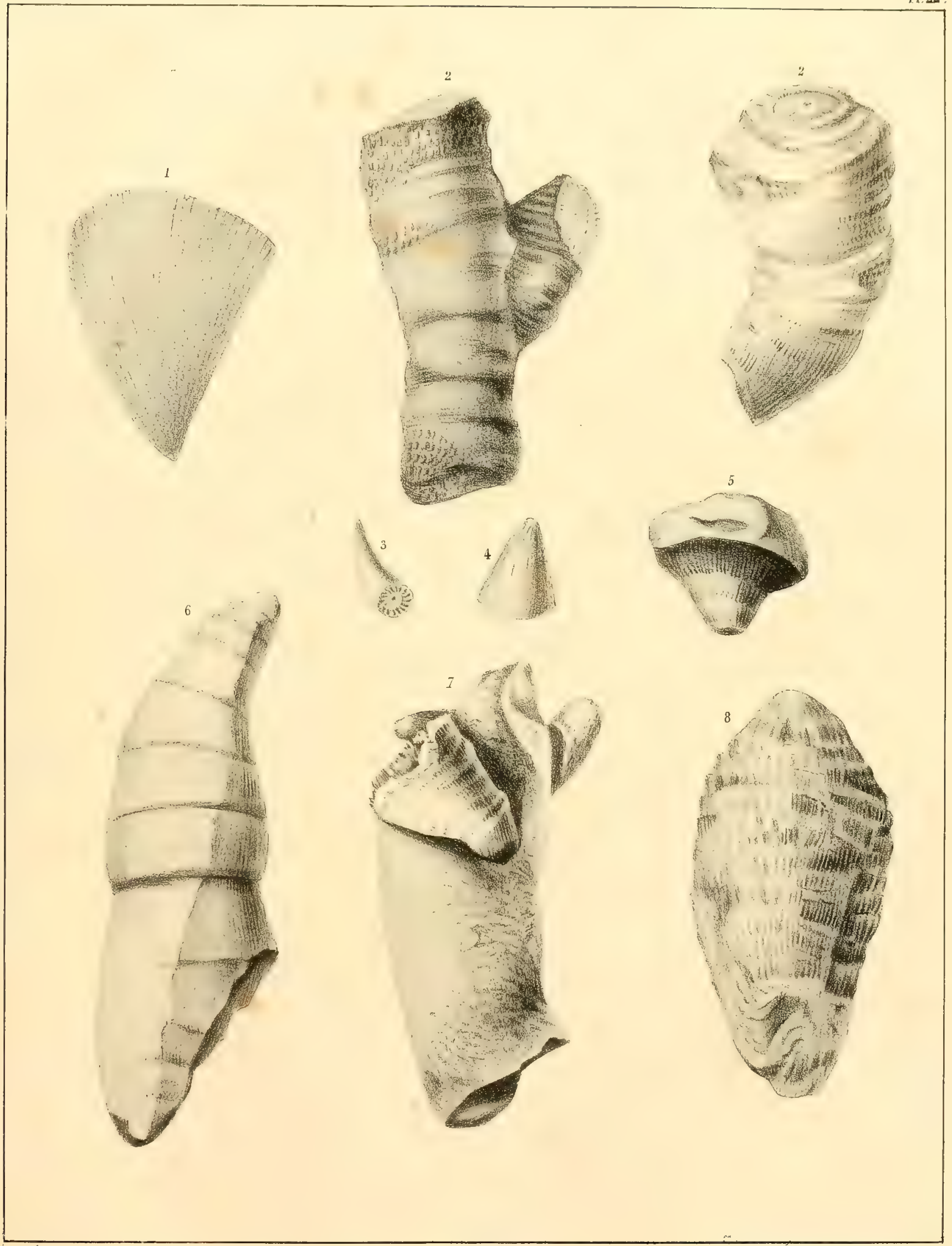

Cyathopliyitum.

Lith d'Aturus, rue de la Harpe.50

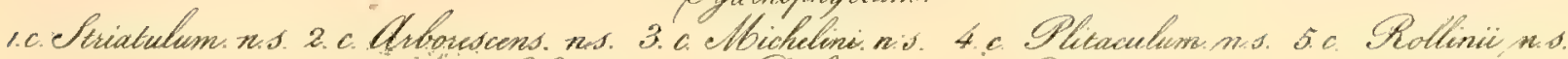

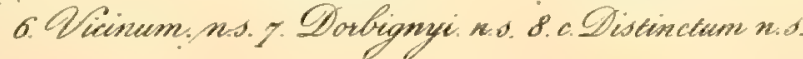





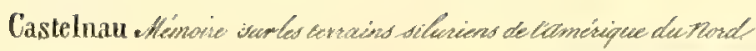

PI. 23
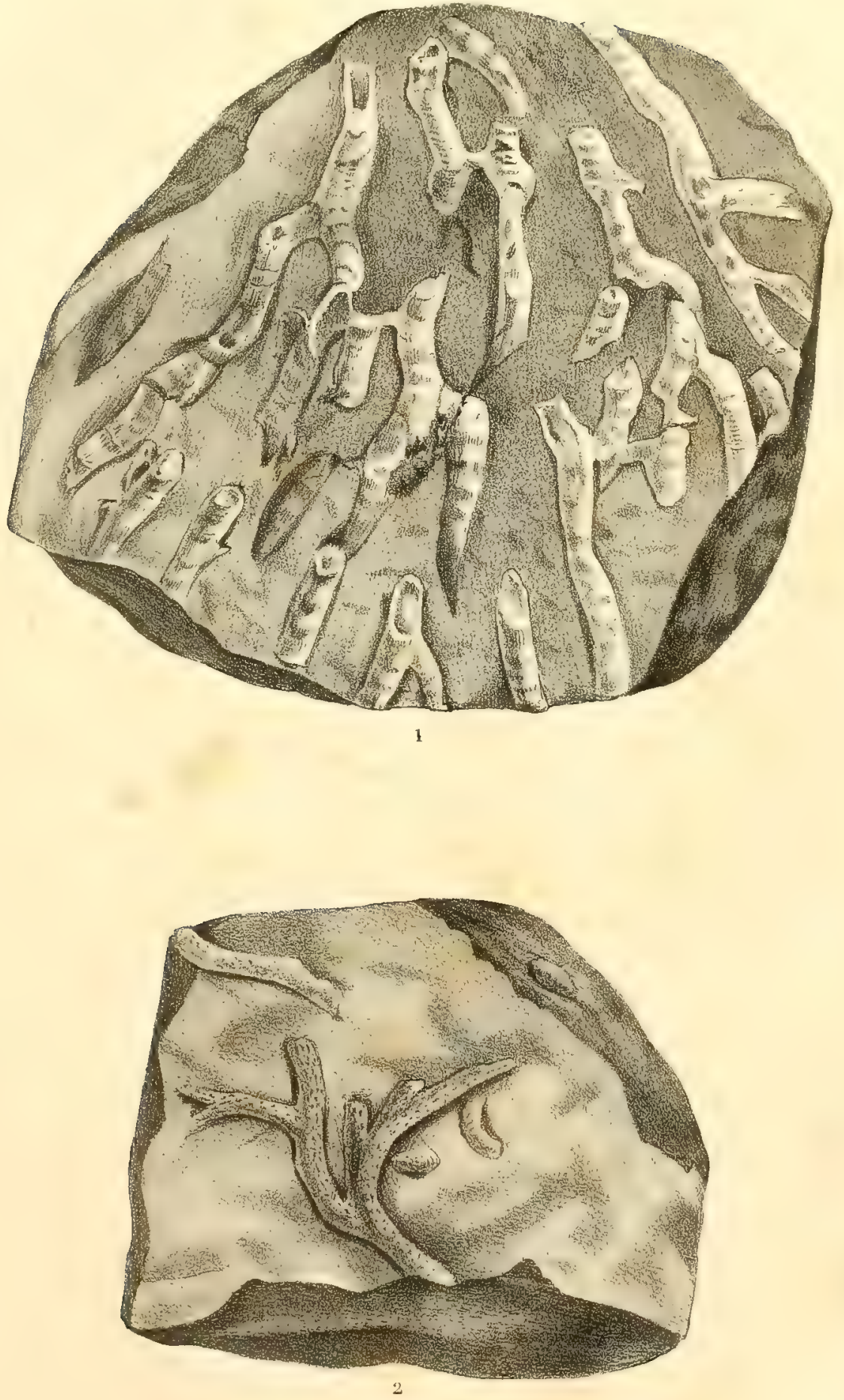

bith. d'Atus, rue de la Harge Ju

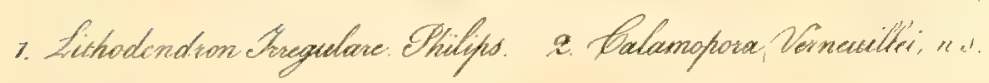


$\therefore \quad \therefore \quad$ HA USA 

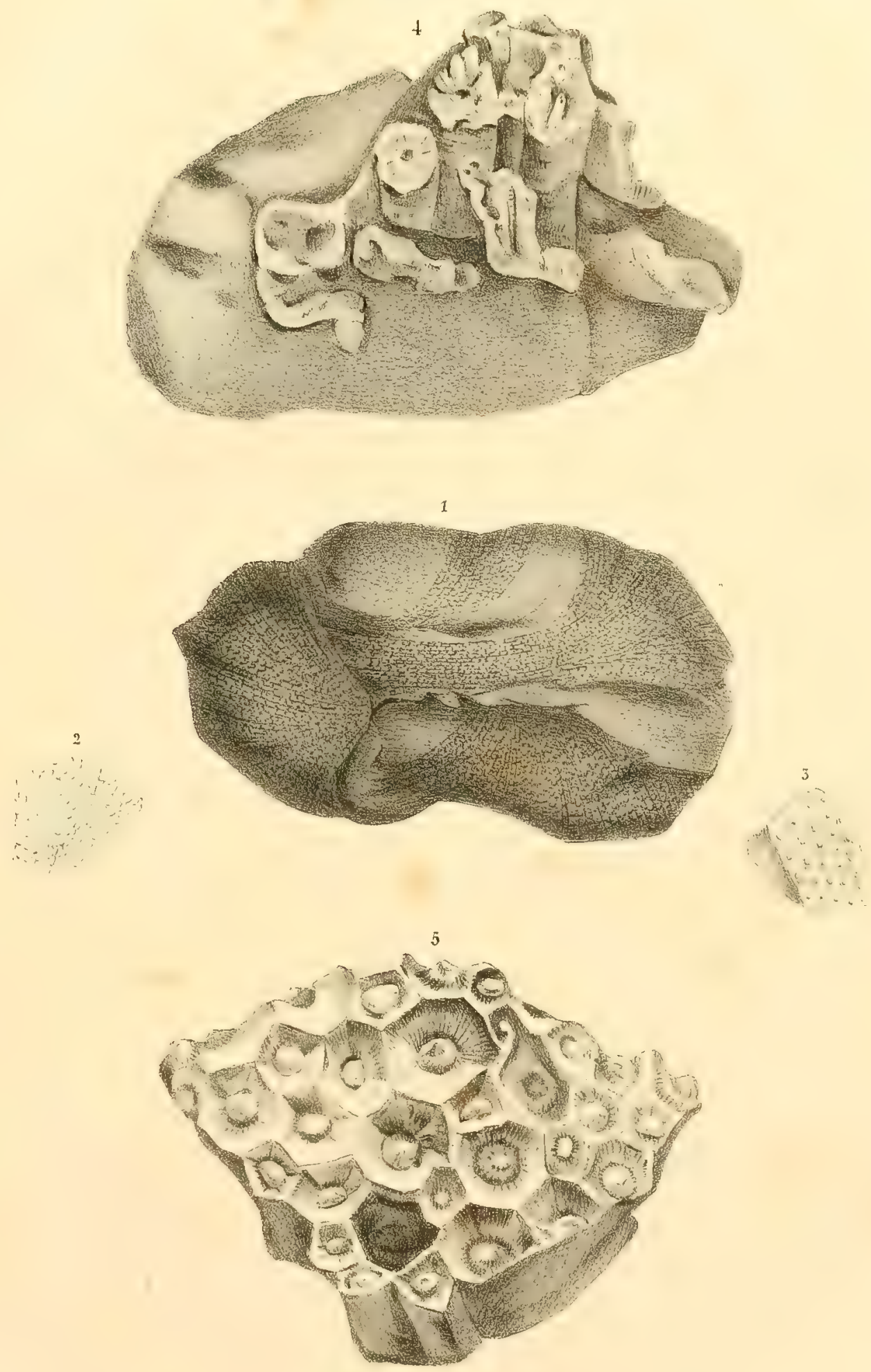

Gorgonix:

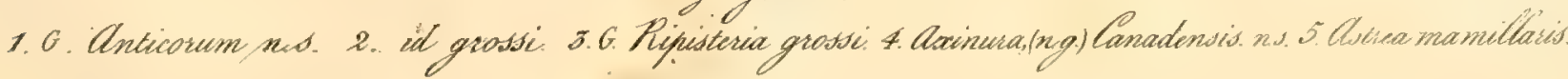





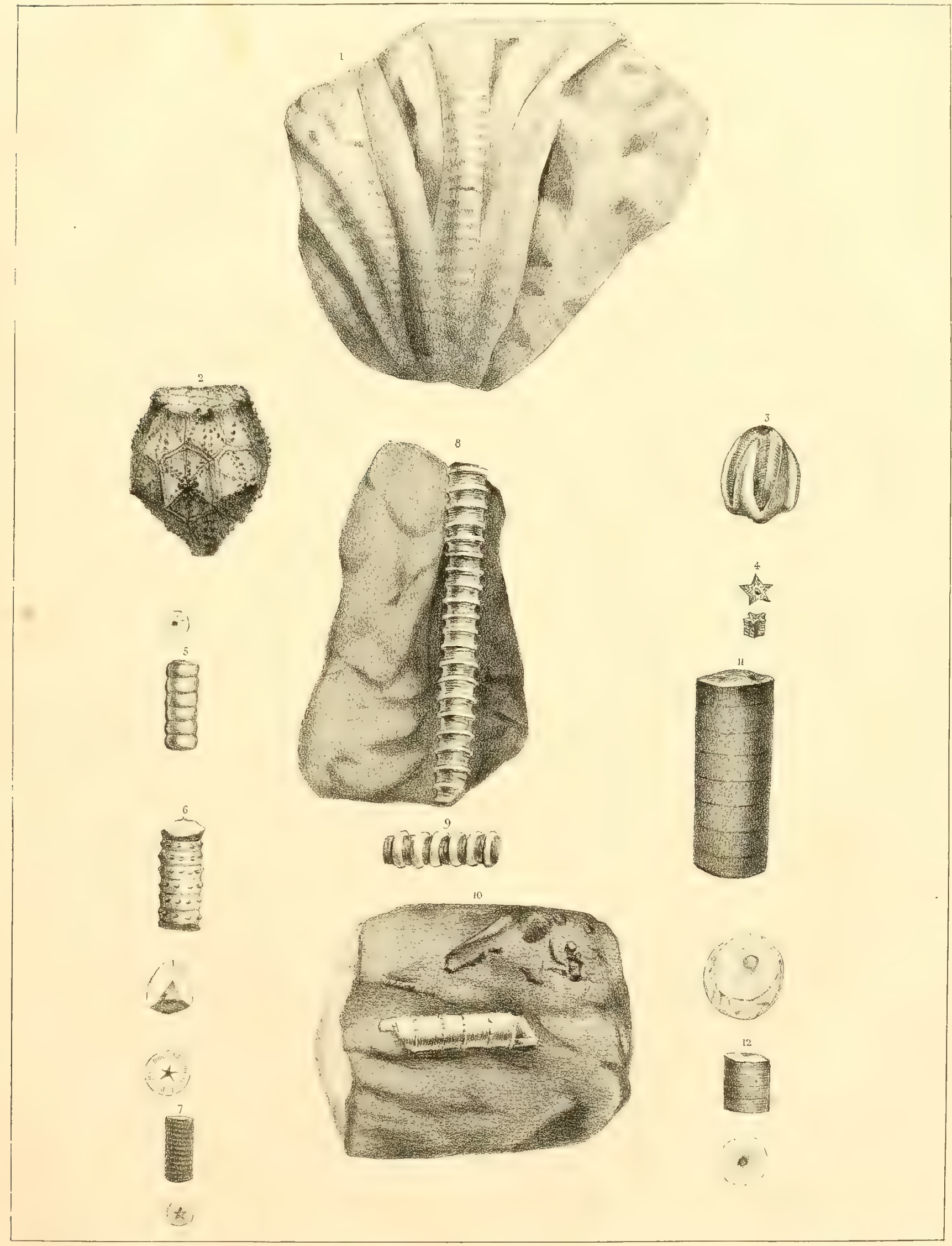

Iith d'Artus, rue de ta Harpe. 50

Curinicles on Cunzoided. 



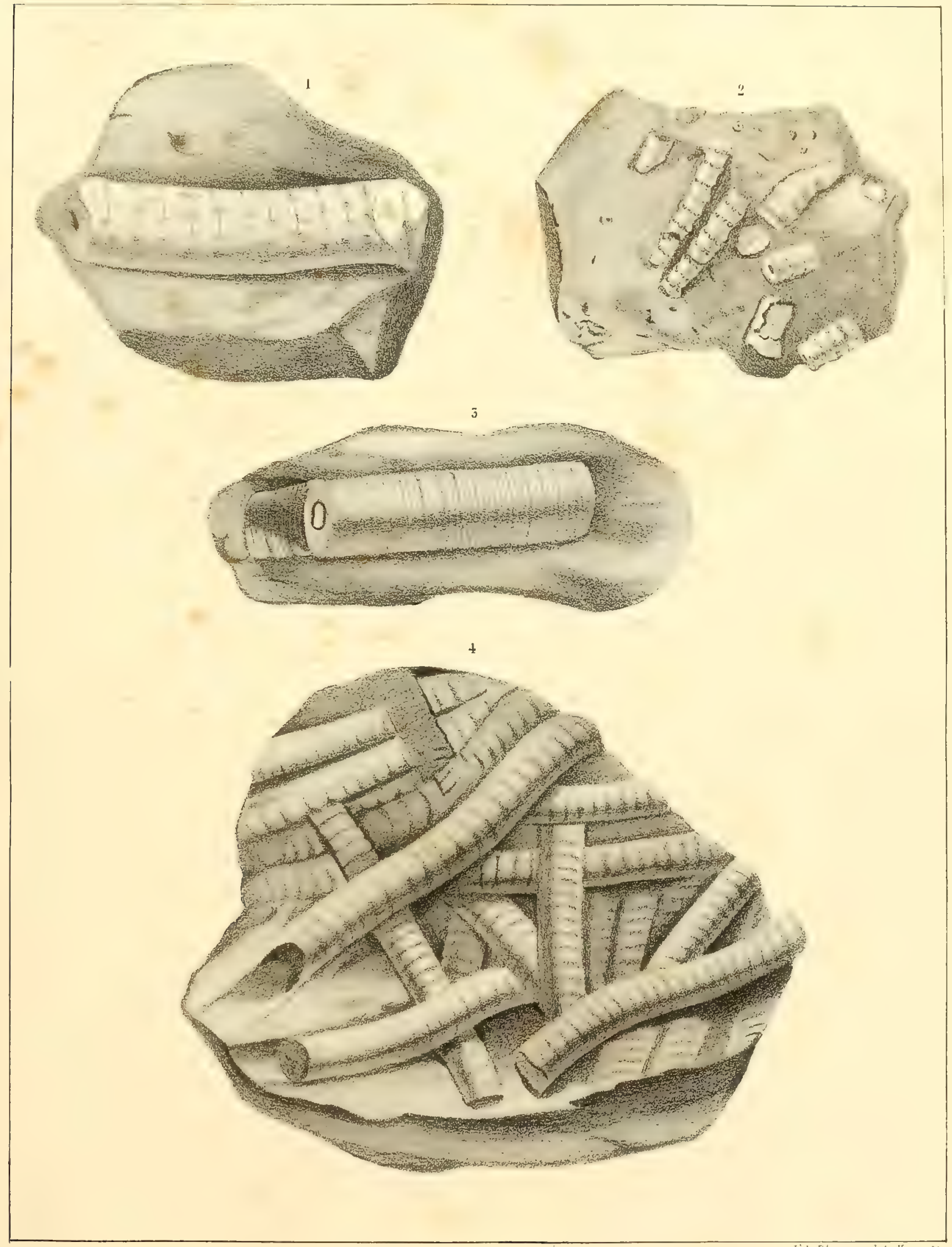





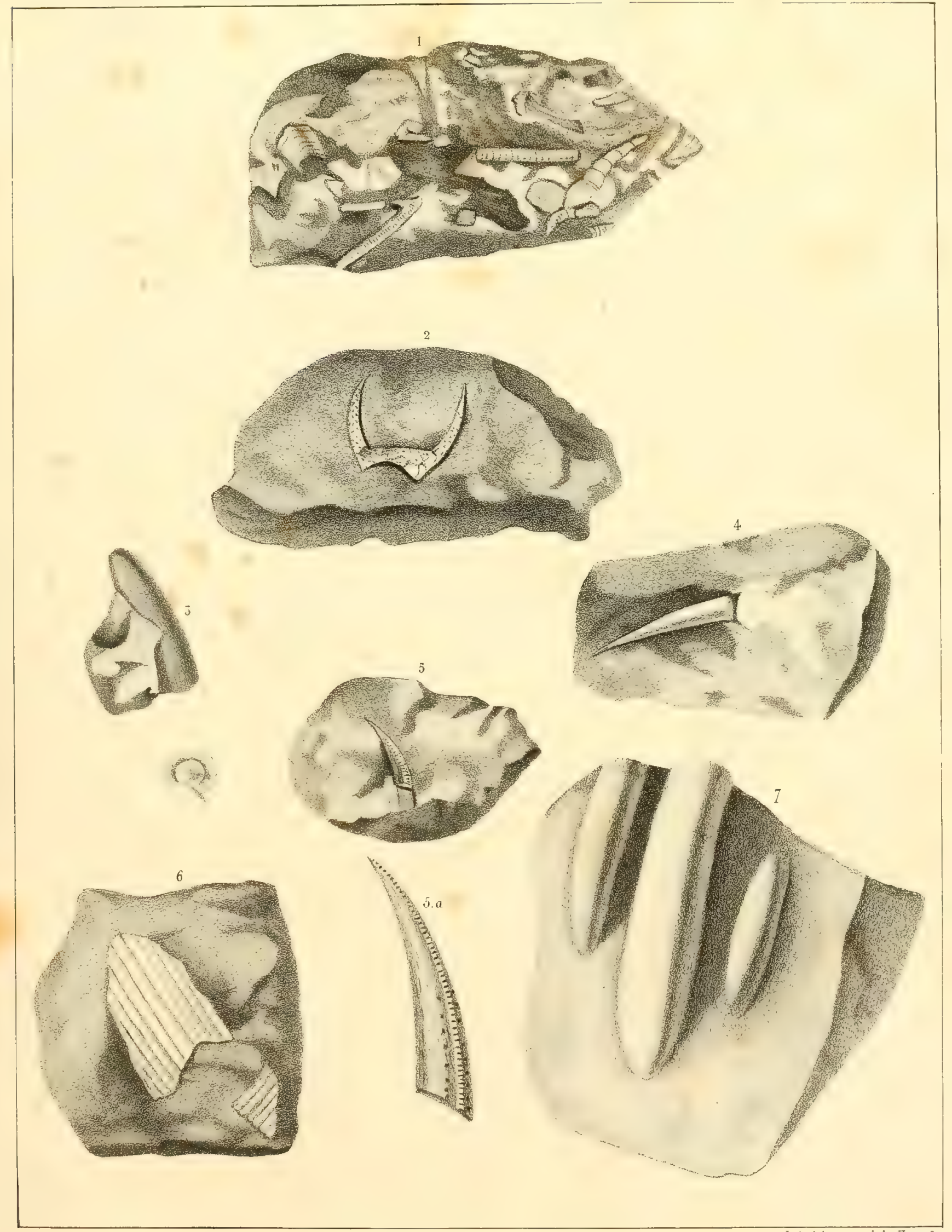

Lith d'Artus, rue do la Harpe $5_{0}$ 


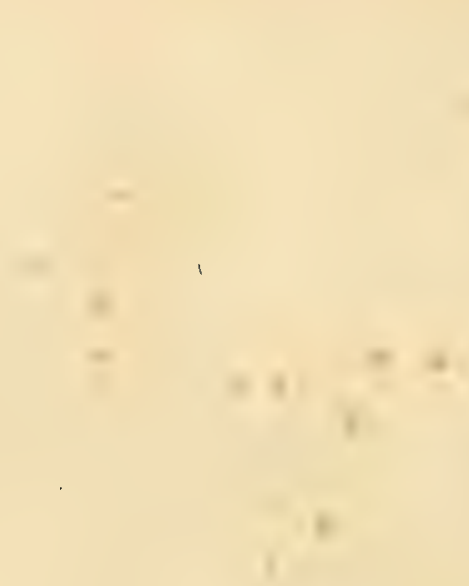

$\because$ YTY

$\quad \quad \therefore \quad$ OM UA

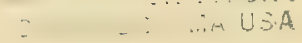

$+$

+ 1

$+2$

3

$-2$

$+2=-1$ 





\section{(x) (4) \\ 4) \\ 21. 1. 1).}

c.

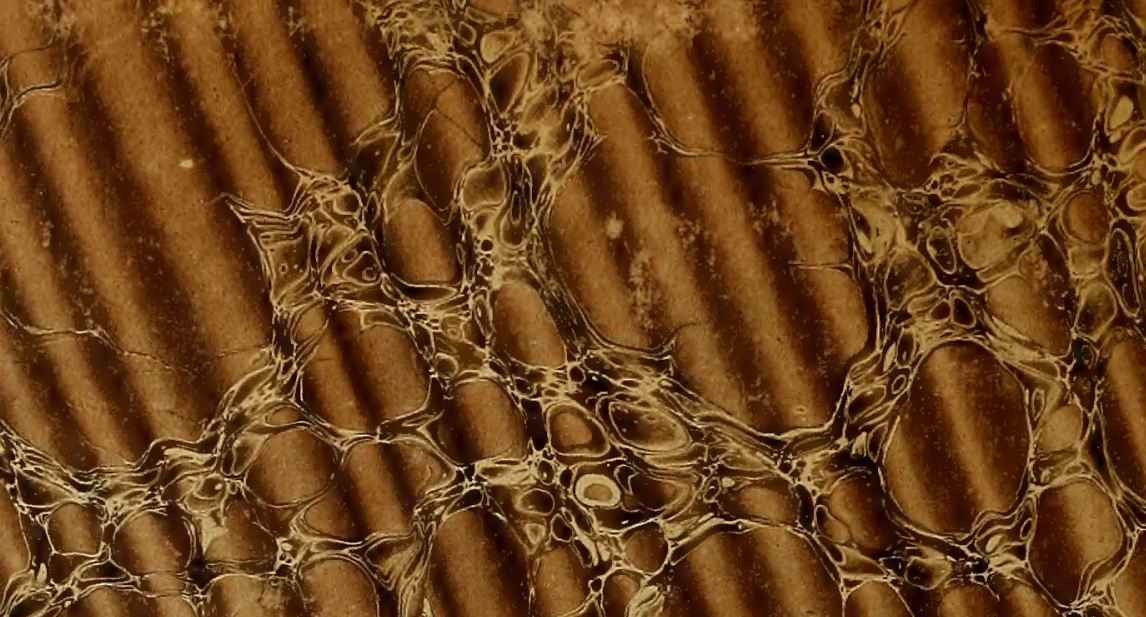

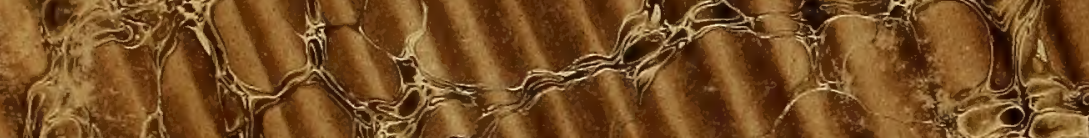

5.

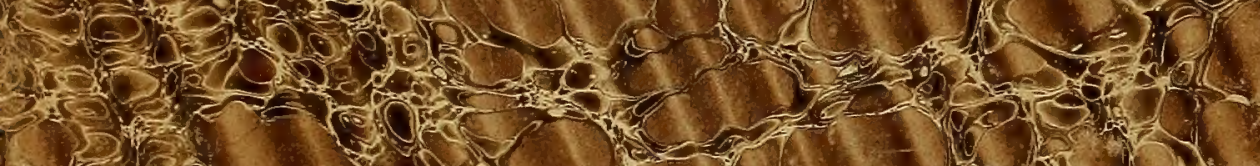
(1)

170

3ives a

1.

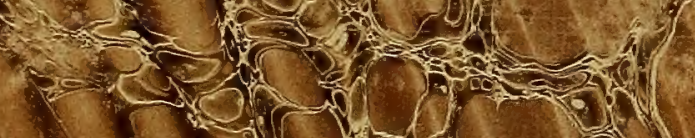

1.X.

2.

7.t. 2011 b

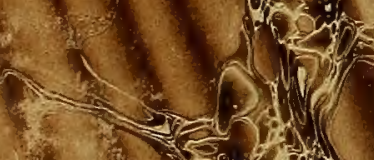

4.

$40,2(x+1)$

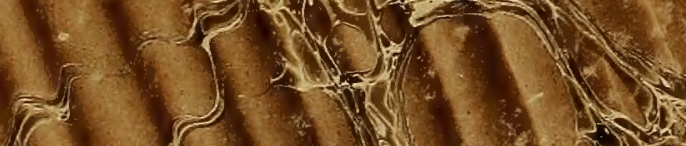

(t)

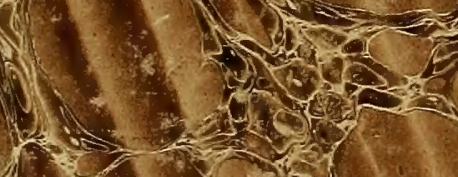

Nom 25

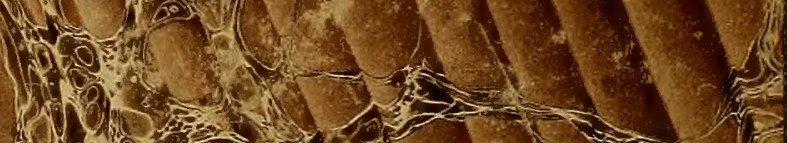

- 200

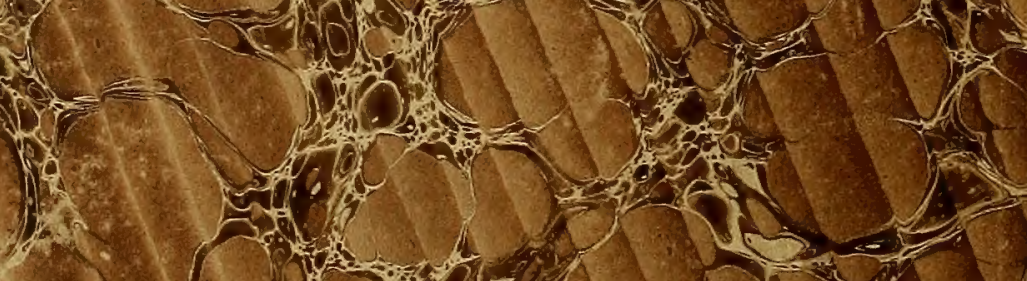

(1)

H.

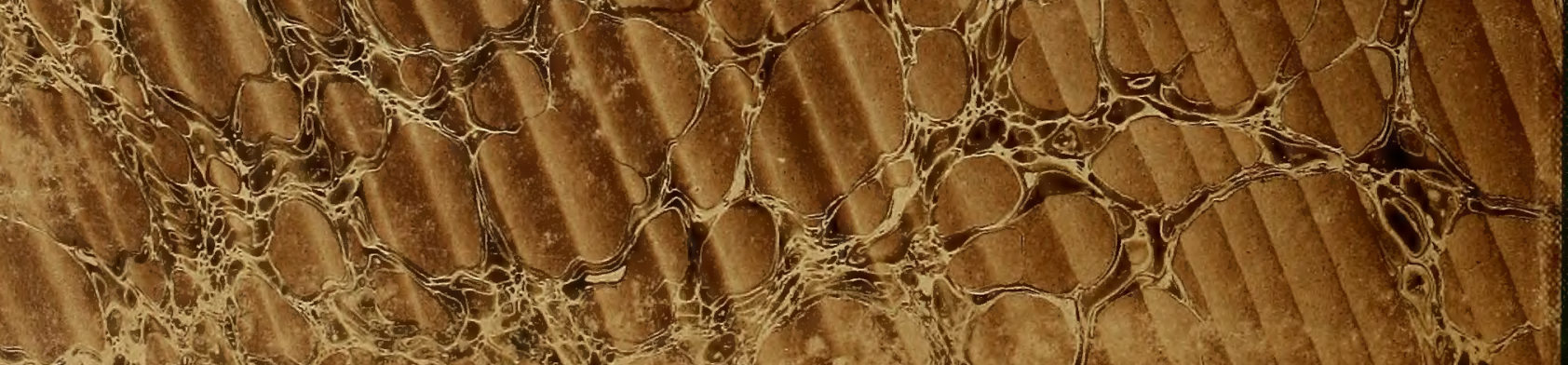

